No. of words abstract: 244; No. of words main text: 6004

No. of figures: 5 ; No. of tables: 2

Supplemental information: 1

\title{
Multivariate Pattern Analysis (MVPA) Reveals Distinct Neural Profiles of Frontoparietal Networks in Boys with Attention-Deficit/Hyperactivity Disorder and Boys with Persistent Depressive Disorder
}

\author{
Veronika Vilgis $^{1 *}$, Debbie Yee ${ }^{2,3 *}$, Tim J. Silk, ${ }^{1,4,5}$ and Alasdair Vance ${ }^{1,5,6}$ \\ ${ }^{1}$ Department of Paediatrics, University of Melbourne, Australia \\ ${ }^{2}$ Washington University in St. Louis, United States \\ ${ }^{3}$ Brown University, United States \\ ${ }^{4}$ Murdoch Children's Research Institute, Australia \\ ${ }^{5}$ School of Psychology, Deakin University, Australia \\ ${ }^{6}$ Royal Children's Hospital, Parkville, Australia
}

*these authors contributed equally to this work

Correspondence to: Debbie Yee, Cognitive, Linguistic \& Psychological Sciences, Brown University, Box 182, Metcalf Research Building, 190 Thayer Street, Providence, RI 02912 Phone: +15166033958

Email:debbie_yee@brown.edu

Short/running title (50 characters): MVPA of Working Memory in ADHD and Depression

Six Keywords: fMRI; MVPA: working memory; ADHD; depression; children 


\begin{abstract}
Working memory deficits are common in attention-deficit/hyperactivity disorder (ADHD) and depression, two common neurodevelopmental disorders with overlapping cognitive profiles but distinct clinical presentation. Multivariate techniques have previously been utilized to understand working memory processes in functional brain networks in healthy adults, but have not yet been applied to investigate how working memory processes within the same networks differ within typical and atypical developing populations. We used multivariate pattern analysis (MVPA) to identify whether brain networks discriminated between spatial vs. verbal working memory processes in ADHD and Persistent Depressive Disorder (PDD). 36 male clinical participants and 19 typically developing (TD) boys participated in a fMRI scan while completing a verbal and a spatial working memory task. Within a priori functional brain networks (frontoparietal, default mode, salience) the TD group demonstrated differential response patterns to verbal and spatial working memory. Both clinical groups show less differentiation than TD, with lower classification accuracies observed in primarily the salience network in the ADHD group and in left frontoparietal and default mode networks in the PDD group. Whereas the TD group's neural profile indicates network response patterns that are sensitive to task demands, the neural profiles of the ADHD and PDD group suggest less specificity in neural representations of spatial and verbal working memory. We highlight within-group classification as innovative tool for understanding the neural mechanisms of how cognitive processes may deviate in clinical disorders, an important intermediary step towards improving translational psychiatry to inform clinical diagnoses and treatment.
\end{abstract}




\section{Introduction}

Half of all mental illnesses begin prior to the age of 15 making them the leading cause of disability in young people worldwide (Kessler et al., 2007). Among the most common diagnosed neuropsychiatric conditions are attention-deficit/hyperactivity disorder (ADHD) and depressive disorders. ADHD and depression present distinctly in everyday life, yet research suggests some commonalities, as both disorders have been associated with impairments in attention (Kessler et al., 2007), executive function (Franklin et al., 2010; Martel, 2007; Martinussen et al., 2005; Matthews et al., 2008) and emotion regulation (Beauregard et al., 2006; Kovacs et al., 2008; Shaw et al., 2014). Additionally, neuroimaging studies have shown similar structural and functional anomalies in frontal, striatal, limbic, parietal and cerebellar brain regions in both disorders (Arnsten \& Rubia, 2012; Cortese et al., 2012; Miller et al., 2015). Although evidence suggests that ADHD and depression potentially share some common cognitive and neural deficits, the extent to which such deficits are similar or distinct across both disorders remains unclear. Insight into how specific impairments (e.g., working memory) differ between ADHD and depression would improve characterization of key cognitive and neural processes disrupted and refine delineation in their underlying neurobiology.

One promising delineation between the working memory deficits often associated with ADHD and depression may be the specific type of working memory impaired. Children and adolescents with ADHD consistently demonstrate working memory deficits and tend to have greater impairments in processing spatial stimuli compared to verbal stimuli in these tasks (Martinussen et al., 2005; Sowerby et al., 2011; Willcutt et al., 2005). Conversely, although adults with depressive disorders also demonstrate working memory deficits (Gohier et al., 2009; Rose et al., 2006), they exhibit more persistent impairments in the verbal domain even after remission and 
independent of age (Gruber et al., 2011; Shilyansky et al., 2016). However, in contrast to the wealth of research implicating executive function deficits in children and adolescents with ADHD (Martel, 2007; Willcutt et al., 2005), much less is understood about the nature of executive function deficits in children and adolescents with depressive disorders (Vilgis et al., 2015). Nevertheless, the few extant studies have observed a deficit in working memory more often (Franklin et al., 2010; Günther et al., 2004; Klimkeit et al., 2005; Matthews et al., 2008; Vance \& Winther, 2020) than not (Korhonen et al., 2002; Maalouf et al., 2011), though the extent to which verbal working memory deficits observed in adults also generalize to children and adolescents is unknown.

Both spatial and verbal working memory tasks consistently engage distinct neural representations in the frontoparietal network (FPN) (Daniel et al., 2016; Rottschy et al., 2012). In typically developing children and adults, the FPN exhibits hemispheric asymmetry, with greater right FPN activation for spatial working memory and left FPN activation for verbal working memory (Thomason et al., 2009). Children and adults with ADHD typically demonstrate less activation in the FPN during working memory tasks (Cortese et al., 2012), with hypoactivation over the right hemisphere compared to controls when processing visuospatial stimuli and bilateral prefrontal hypoactivation during a verbal task (Silk et al., 2005; Vance et al., 2007). Conversely, several studies in adults with depression have observed atypical activation of the left prefrontal cortex during working memory (Barch et al., 2003; Vasic et al., 2007; Walter et al., 2007), a pattern also observed in a pediatric sample of boys with Persistent Depressive Disorder (PDD) during a spatial task (Vilgis et al., 2014). Because disorder-specific hemispheric asymmetries exist independent of the type of stimulus material being processed, it is difficult to determine the extent to which atypical activation in ADHD and depression arises from dysregulated processing of a specific type of working memory (e.g., spatial vs. verbal) versus a more general neurological 
deficit associated with either disorder. Therefore, in order to develop greater understanding into how the neural patterns that underlie spatial and verbal working memory are altered in this network, it is necessary to perform a systematic comparison of how left and right FPN are disrupted in both working memory tasks in both ADHD and depression.

An important additional consideration is that networks that interact with the FPN may contribute to working memory deficits or play a compensatory role in the two disorders. In particular, the FPN interacts with the salience and default-mode network to support key working memory processes (Liang et al., 2016). The salience network (SN) plays a central role via continuously monitoring for endogenous and exogenous salient stimuli in order to facilitate the dynamic switching between internally directed, self-focused cognition carried out by the defaultmode network (DMN) and externally directed cognition supported by the FPN (Menon \& Uddin, 2010; Seeley, 2019). In children with ADHD, the absence of explicit task demands has been associated with weaker and more variable interconnectivity between FPN, SN, and DMN, including shorter and less persistent brain states (Cai et al., 2019). Similarly, in patients with depression, symptoms of rumination, emotional over-reactivity, and cognitive regulation of affective information have been associated with altered functional connectivity in the DMN, SN and FPN respectively (Hamilton et al., 2013; Manoliu et al., 2014). This compelling evidence suggests that the locus of working memory impairments in ADHD and depression likely arises from dysregulation of these core networks and their interactions. Yet, how neural patterns within each network support different types of working memory, and more critically, how these patterns putatively deviate in ADHD and depression, remains an enigma.

Thus, an outstanding question relates to understanding the precise mechanisms driving network-level differences in spatial and verbal working memory in ADHD and depression. Here, 
we present an innovative approach that combines network-based and multivariate analyses to investigate how neural patterns of spatial vs. verbal working memory putatively differ within clinical groups. Network-based approaches are uniquely powerful, as they provide a systematic approach for investigating neural systems underpinning cognitive function (Cole et al., 2014). Multivariate pattern analysis (MVPA) is a powerful machine learning method utilized to classify brain voxels to predict whether they carry information regarding distinct categories, tasks, or other cognitive states (Haxby et al., 2014; Mumford et al., 2012; Yang et al., 2012). Importantly, MVPA has been used to successfully dissociate between neural representations of cognitive tasks in prefrontal and parietal cortices (Etzel et al., 2016; Wisniewski et al., 2015; Woolgar et al., 2015). This precedent for utilizing MVPA to decode neural task representations strongly motivates the adaptation of this cutting-edge technique for examining networks that support working memory processes (e.g., FPN, SN, DMN).

Whereas MVPA has been previously adopted to investigate cognitive processes in typical development (Chow et al., 2018), such approaches have not yet been applied to understand how they diverge within clinical populations. In particular, MVPA may serve as a powerful tool that can systematically evaluate how distinctness of neural patterns underpinning different cognitive processes within the same brain networks may differ across typical vs atypical populations. Moreover, this data-driven method is aligned with computational psychiatry, an emerging field that promotes computationally rigorous approaches to improve the understanding, prediction, and treatment of mental disorders (Dwyer et al., 2018; Wiecki et al., 2015). Thus, combining MVPA with a network-based approach for clinical neuroimaging data provides a promising novel direction for improving mechanistic understanding of the distinctness of neural representations underlying spatial and verbal working memory tasks in ADHD and depression. 
In the current study, we utilize MVPA to decode neural patterns underpinning spatial vs. verbal working memory in a priori brain networks (Hebart \& Baker, 2018) within three different groups: typical development (TD), ADHD and Persistent Depressive Disorder (PDD). We focus on PDD as a more chronic developmental disorder more similar to ADHD in its stability over time (versus major depressive disorder characterized by relatively shorter episodes of negative mood). An innovative feature of our within-group classification analysis entails neural decoding of spatial vs. verbal working memory processes in the same network. Given the known issues with how fMRI decoding results differ based upon the number of voxels in regions of interest (ROI) (Haynes, 2015), our approach of utilizing the same ROI for each decoding facilitates clear comparison of how neural representations of working memory processes are uniquely characterized within each clinical group. We predict distinct neural patterns in left and right FPN for spatial vs. verbal working memory processes in typical development. Moreover, we expect a double dissociation with an atypical pattern for the right but not left FPN in the ADHD group, and a deviant pattern for the left but not right FPN in the PDD group. Additionally, we examine neural patterns in the SN and DMN, two prominent networks known to interact with the FPN and previously identified as functioning atypically in ADHD and depression (Menon, 2011). Our objective was to identify shared and unique network response patterns for each developmental disorder, which may inform disorder-specific neural profiles underpinning well-known behavioral deficits in spatial and verbal working memory.

\section{Methods and Materials ${ }^{1}$}

\section{Participants}

\footnotetext{
${ }^{1}$ All task scripts and analysis scripts are uploaded on our OSF repository: https://osf.io/a5349/
} 
39 male children and adolescents were recruited through an outpatient pediatric psychiatry clinic, met inclusion criteria for the study, and agreed to participate in the MRI scan. Of those, 17 fulfilled DSM-IV (American Psychiatric Association, 2000) diagnostic criteria for PDD (labelled as Dysthymic Disorder in DSM-IV) and 22 for a diagnosis of ADHD - Combined Type (i.e. at least six symptoms of inattentive and hyperactive/impulsive symptoms were met). All young people and their caregivers were interviewed using the Anxiety Disorders Interview Schedule for Children (Silverman et al., 2001). Caregivers also completed the Conners' Parent Rating Scale long version (Conners et al., 1998) and the Child Behavior Checklist (CBCL) (Achenbach, 1991) and the young person completed the Children's Depression Inventory (Kovacs, 2003). An experienced child and adolescent psychiatrist (AV) confirmed each diagnosis. Participants were included if they were male, right-handed, free of metal implants (MRI compatibility) and with a full-scale IQ above 70. Exclusion criteria were the presence of an intellectual disability, learning disorder or known neurological or endocrine condition. Participants were also excluded if they had a previous diagnosis of an Autistic Spectrum Disorder, Bipolar Disorder or Psychotic Disorder. All clinical participants in the PDD and ADHD group had that disorder as primary diagnosis, but comorbidities of Oppositional Defiant Disorder, Conduct Disorder and anxiety disorders were permitted. Participants with ADHD $(n=6)$ who were treated pharmacologically at time of testing withheld their stimulant medication at least $48 \mathrm{~h}$ before participating in the MRI scan. Only one participant with PDD had been started on antidepressant medication prior to scanning. After excluding two ADHD participants due to excessive head motion and one PDD participant due to task performance, the final sample comprised 16 boys with PDD and 20 boys with ADHD. 19 typically developing participants (TD) and their caregivers were recruited through local schools. They completed the same questionnaires and semistructured clinical interviews as the clinical 
participants to ascertain normal psychological functioning. None of the TD met diagnostic criteria for any psychiatric diagnosis. An abbreviated IQ test was conducted with two subtests of the Verbal Comprehension Index (Similarities and Vocabulary) and two subtests of the Perceptual Reasoning Index (Block Design and Matrix Reasoning) (Wechsler, 2003) and scores were calculated as previously described (Crawford et al., 2010). All procedures were approved by the local Human Research Ethics Committee. All parents/guardians and young people gave informed written consent to participate in the study.

\section{fMRI Data Acquisition}

Images were acquired on a 3T Siemens TIM Trio scanner (Siemens, Erlangen Germany) at the Royal Children's Hospital, Melbourne. Participants lay supine with their head supported in a 32-channel head coil. High-resolution T1-weighted structural MRI images were acquired for each participant $\left(\mathrm{TR}=1900 \mathrm{~ms}, \mathrm{TE}=2.24 \mathrm{~s}, \mathrm{FA}=90^{\circ}\right.$, in-plane pixels $\left.=0.9 \times 0.9 \mathrm{~mm}\right)$ prior to the functional scan. For functional imaging, T2*-weighted gradient-echo echo-planar images (EPI) were acquired $\left(\mathrm{TR}=2700 \mathrm{~ms}, \mathrm{TE}=40 \mathrm{~ms}, \mathrm{FA}=90^{\circ}, 39\right.$ axial slices (co-planar with AC-PC) with $3.0 \mathrm{~mm}$ isotropic resolution). A total of 158 image volumes were acquired per $7 \mathrm{~min} 10 \mathrm{~s}$ sequence. This was run twice, one for each working memory task. Participants' responses were recorded with a scanner compatible two button-box (Fibre-optic response pads, Current Designs, Philadelphia, PA).

fMRI Task

A Sternberg type working memory task divided into verbal and spatial working memory components was adapted from Thomason et al. (2009). In the verbal task, participants viewed an 
array of capital letters, two in the low load condition and six in the high load condition. In the spatial task, either one or five black dots were presented randomly. After a $3000 \mathrm{~ms}$ delay, a single letter in lower case (verbal task) or a circle (spatial task) was presented for $1500 \mathrm{~ms}$ while participants indicated by button-press whether the probe matched the identity (verbal task) or location (spatial task) of the initial cues. Both tasks included control conditions that matched experimental conditions as much as possible (motor response, decision-making, visual stimuli, luminance, total trial length), except for the $3000 \mathrm{~ms}$ delay which was shortened to $100 \mathrm{~ms}$. Probes matched the target $50 \%$ of the time. For each task, a total of 64 trials (32 experimental, 32 control) were presented in 16 pseudorandomly alternating blocks of four trials. Here, we combined high and low load conditions to optimize the beta estimates used in the MVPA analysis. Maximizing the number of blocks for within-subject classification improves accuracy via reducing overall noise of the beta estimates (Ku et al., 2008) and maximizes statistical power (Allefeld \& Haynes, 2014). A more detailed task description is provided in the Supplementary Material and a schematic representation is shown in Figures $1 \mathrm{a}$ and $1 \mathrm{~b}$. 
bioRxiv preprint doi: https://doi.org/10.1101/2021.03.09.434662; this version posted July 16, 2021. The copyright holder for this preprint (which was not certified by peer review) is the author/funder, who has granted bioRxiv a license to display the preprint in perpetuity. It is made available under aCC-BY-ND 4.0 International license.

a Verbal Working Memory Task

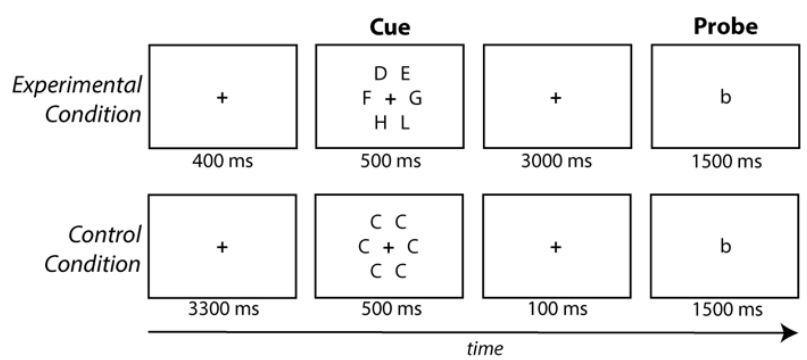

b Spatial Working Memory Task
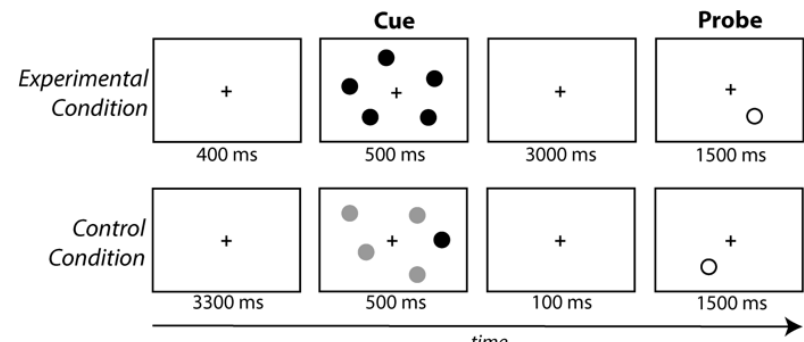

c Multivariate Decoding of Verbal vs. Spatial Working Memory Beta Estimates

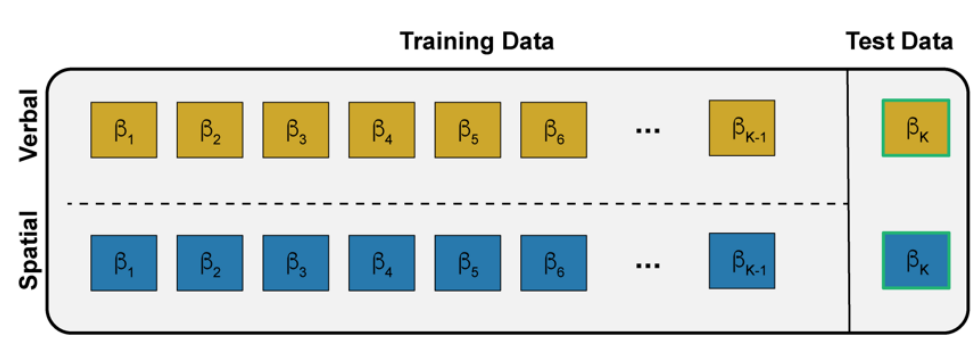

$\mathrm{K}=$ number of subjects
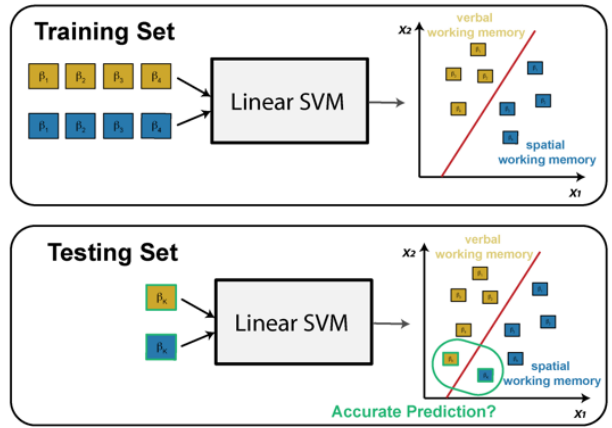

Figure 1 a) Schematic of the Verbal Working Memory Task. Participants were cued with an array of uppercase capital letters. After $3000 \mathrm{~ms}$ delay, a single lowercase letter was presented for $1500 \mathrm{~ms}$ while participants indicated by button-press whether the probe matched the identity of the initial cues. The control condition matched the experimental condition in as many elements as possible (motor response, decision-making, visual stimuli, luminance, total trial length), except for the $3000 \mathrm{~ms}$ delay which was shortened to $100 \mathrm{~ms}$. b) Schematic of the Spatial Working Memory Task. This task was similar to the verbal task, except the cue was a set of black dots, and participants were tasked with indicating whether the circle probe matched the location of the initial task cues. c) Multivariate Decoding of Spatial vs. Verbal Working Memory Beta Estimates. A linear support vector machine (SVM) classifier with K-fold cross validation was implemented for each network within each group, with $\mathrm{K}$ equal to the number of subjects in each group. The classifier was trained on beta estimates for spatial and verbal working memory from K-1 subjects and tested on the remaining subject in that group. The process was repeated for the control conditions. Permutation tests $(n s i m=1000)$ evaluated whether observed classification accuracies for each network were statistically significant above chance.

\section{fMRI Preprocessing}

Subject data was preprocessed using AFNI (https://afni.nimh.nih.gov/) (Cox, 1996). The

EPI volumes were realigned, slice-timing corrected, registered to an MNI152 atlas, and normalized. EPI volumes were smoothed using a 4 mm FWHM Gaussian kernel to improve signal

to noise ratio, which has been demonstrated in previous work (Gardumi et al., 2016; Woolgar et al., 2015). A general linear model was applied to each subject to extract block-level beta estimates for each of the four block types: spatial experimental, spatial control, verbal experimental and 
verbal control conditions. The design matrix was estimated using AFNI's 3dDeconvolve function, and a generalized least squares time series fit with REML estimation of the temporal autocorrelation structure (3dREMLfit) was applied to estimate individual betas for the four regressors per subject. Each block lasted 21.6 seconds ( 8 TRs), and each run contained 16 blocks. These extracted beta estimates were fed into the linear Support Vector Machine (SVM) to classify spatial vs. verbal tasks for each of the 5 networks. Six motion parameters were included as GLM nuisance regressors. TRs (current and previous) were censored if the derivative values had a Euclidean norm above $3.5 \mathrm{~mm}$.

To ensure the working memory tasks reliably activated frontoparietal regions in each clinical group, general linear tests were applied to the estimated beta weights to calculate task activation for spatial and verbal working memory independently for each participant. Within each group, AFNI's 3dttest++ function was applied to generate statistical maps for the average of the spatial and working memory conditions. Significant clusters for each task condition and group (thresholded at $\mathrm{p}<.001$, cluster corrected with threshold $\alpha=.01$ ) are shown in Figure 4.

\section{ROI Masks}

The ROI masks were selected from https://www.fmrib.ox.ac.uk/datasets/brainmap+rsns/ and have been described previously (Smith et al., 2009). We focused on the left and right FPN, key networks supporting working memory related activity and in accordance with our predictions that classification accuracy would differ between the groups given the previous literature. In addition, we included the DMN and the $\mathrm{SN}$, as these networks dynamically interact with the FPN to support working memory. We also included the sensorimotor (SM) network as control network, where we do not expect significant differences between tasks or groups. All brainmaps were 
resampled to match the dimensions of the data $(3 \times 3 \times 3 \mathrm{~mm}$ isotropic), thresholded at 3.5 , and binarized to create masks for each of the networks. The ROIs are shown in Figure 3a.

\section{Multivariate Pattern Analysis (MVPA)}

Multivariate pattern analysis (MVPA) was performed on each of the 5 networks (left and right FPN, SN, DMN, SM) using the Decoding Toolbox (Hebart et al., 2015), and custom MATLAB code. All classifications implemented a linear SVM classifier using a classification kernel from libsvm package with a fixed cost parameter $(\mathrm{c}=1)$. K-fold cross-validation was performed for each group using a leave-one-run-out protocol, with $\mathrm{K}$ equal to the number of subjects in each group. Here, the classifier was trained on data from K-1 subjects (per group) and tested on the left out remaining subject in that group. The beta-estimates were used to train and test our classifier (Pereira et al., 2009) on spatial vs. verbal working memory (See Figure 1c). Critically, the utilization of $\mathrm{K}$-fold cross-validation allows for better generalization of the classification model to novel datasets (e.g., less overfitting to the dataset).

The linear SVM classifier generates signal detection metrics that could be used to compare the classification accuracy (e.g., the proportion of correctly classified observations), as well as additional performance metrics such as the model's sensitivity (e.g., true positive rate) and model's specificity (e.g., true negative rate). In the current study, we summarize these signal detection metrics into area under the curve (AUC) parameter, which allows us to incorporate both sensitivity and specificity measures to evaluate the intrinsic accuracy of the diagnostic test and compare classifier performance measures between networks and groups (Zhu et al., 2010). Greater detail of these performance metrics is provided in the Supplemental Material. Permutation tests $(n s i m=1000)$ evaluated whether the observed cross-validated classification accuracies for each 
network were statistically significant above chance (Etzel \& Braver, 2013; Hebart et al., 2015).

The procedure was repeated for the spatial versus verbal control conditions.

\section{Results}

\section{Clinical and Behavioral Results}

We first characterized how clinical symptoms differed at the group level, which would inform subsequent within-group differences. Both clinical groups exhibited greater levels of externalizing and internalizing symptoms compared to the TD group and lower scores on IQ measures. As expected, both clinical groups differed from each other in scores of internalizing symptoms $(\mathrm{PDD}>\mathrm{ADHD})$ and related global ADHD and restless symptoms (ADHD $>$ PDD). All clinical measures are listed in Table 1.

Table 1: Means (M) and standard deviations (SD) of demographic and clinical variables for each group.

\begin{tabular}{|c|c|c|c|c|c|c|}
\hline & $\begin{array}{c}\operatorname{ADHD}(\mathrm{n}=20) \\
M(S D)\end{array}$ & $\begin{array}{c}\text { PDD }(\mathrm{n}=16) \\
M(S D)\end{array}$ & $\begin{array}{c}\text { TD }(\mathrm{n}=19) \\
M(S D)\end{array}$ & $F(2,52) *$ & $p$ & $\begin{array}{c}\text { Follow-up t-test } \\
\text { ( } \text { Bonf. corrected) }\end{array}$ \\
\hline Age & $12.77(19.6)$ & $12.94(2.05)$ & $13.04(2.4)$ & 0.0799 & n.s. & \\
\hline $\begin{array}{l}\text { CDI Sum } \\
\text { (self-report) }\end{array}$ & $10.00(6.59)$ & $14.88(10.37)$ & $4.16(2.89)$ & $\begin{array}{c}10.1 \\
(F(2,51))\end{array}$ & $<0.001$ & $\begin{array}{l}\mathrm{ADHD}>\mathrm{TD}(.04) \\
\mathrm{DD}>\mathrm{TD}(<.001)\end{array}$ \\
\hline $\begin{array}{l}\text { CBCL } \\
\text { Internalizing (p) }\end{array}$ & $62.35(9.70)$ & $72.5(7.39)$ & $45.68(10.51)$ & 36.726 & $<.001$ & $\begin{array}{l}\mathrm{DD}>\mathrm{ADHD}(.007) \\
\mathrm{ADHD}>\mathrm{TD}(<.001) \\
\mathrm{DD}>\mathrm{TD}(<.001)\end{array}$ \\
\hline $\begin{array}{l}\text { CBCL } \\
\text { Externalizing (p) }\end{array}$ & $67.50(11.38)$ & $63.31(7.32)$ & $45.11(7.69)$ & 32.45 & $<.001$ & $\begin{array}{l}\mathrm{ADHD}>\mathrm{TD}(<.001) \\
\mathrm{DD}>\mathrm{TD}(<.001)\end{array}$ \\
\hline $\begin{array}{l}\text { CPRS } \\
\text { Global Index (p) }\end{array}$ & $75.37(11.48)$ & $65.6(10.46)$ & $47.26(5.41)$ & $\begin{array}{c}43.465 \\
(F(2,50))\end{array}$ & $<.001$ & $\begin{array}{l}\mathrm{ADHD}>\mathrm{DD}(.012) \\
\mathrm{ADHD}>\mathrm{TD}(<.001) \\
\mathrm{DD}>\mathrm{TD}(<.001)\end{array}$ \\
\hline CPRS Restless (p) & $72.63(14.83)$ & $63.53(8.75)$ & $48.11(5.87)$ & $\begin{array}{c}25.763 \\
(F(2,50))\end{array}$ & $<.001$ & $\begin{array}{l}\mathrm{ADHD}>\mathrm{DD}(.05) \\
\mathrm{ADHD}>\mathrm{TD}(<.001) \\
\mathrm{DD}>\mathrm{TD}(<.001)\end{array}$ \\
\hline $\begin{array}{l}\text { Verbal } \\
\text { Comprehension } \\
\text { Index }\end{array}$ & $95.79(10.20)$ & $95.6(10.11)$ & $111.06(8.34)$ & $\begin{array}{c}15.147 \\
(F(2,49))\end{array}$ & $<.001$ & $\begin{array}{l}\mathrm{TD}>\mathrm{ADHD}(<.001) \\
\mathrm{TD}>\mathrm{DD}(<.001)\end{array}$ \\
\hline $\begin{array}{l}\text { Perceptual } \\
\text { Reasoning Index }\end{array}$ & $89.74(8.68)$ & $94.4(13.02)$ & $108.78(12.17)$ & $\begin{array}{c}14.021 \\
(F(2,49))\end{array}$ & $<.001$ & $\begin{array}{l}\mathrm{TD}>\mathrm{ADHD}(<.001) \\
\mathrm{TD}>\mathrm{DD}(.002)\end{array}$ \\
\hline
\end{tabular}

CDI $=$ Child Depression Inventory, $\mathrm{CBCL}=$ Child Behavior Checklist; CPRS $=$ Conners Parent Rating Scale; $(\mathrm{p})=$ parent-rated 
bioRxiv preprint doi: https://doi.org/10.1101/2021.03.09.434662; this version posted July 16, 2021. The copyright holder for this preprint (which

was not certified by peer review) is the author/funder, who has granted bioRxiv a license to display the preprint in perpetuity. It is made available under aCC-BY-ND 4.0 International license.

MVPA OF WORKING MEMORY IN ADHD AND DEPRESSION

With regard to the behavioral performance on the two working memory tasks, within each group, reaction times (RT) and accuracy did not differ between the verbal and spatial task components (Accuracy: PDD $t(15)=0.37, p=0.717$; ADHD $t(19)=0.61, p=0.547$; $t(17)=-0.31$, $p=0.758 ;$ RT: PDD $t(15)=-1.21, p=0.246 ;$ ADHD $t(19)=-0.97, p=0.342 ;$ TD $t(18)=-1.27$, $p=0.222$ ). In the control conditions, behavioral performance was similar between both tasks, though there was a trend towards faster reaction times in the verbal than spatial control condition in the PDD group (Accuracy: PDD $t(15)=0.92, p=0.370$; ADHD $t(19)=-0.50, p=0.624$; TD $t(17)=0.89, p=0.385 ; \mathrm{RT}:$ PDD $t(15)=-2.20, p=0.044^{*}$, ADHD $t(19)=-1.43 ; p=0.169 ;$ TD $t(18)=-$ 1.62, $p=0.123$ ). Task performance measures are illustrated in Figure 3 and provided in Table S1 in the Supplementary Material. Additionally, motion did not differ between verbal and spatial working memory conditions nor control conditions (See Table S2 in Supplementary Material).

a

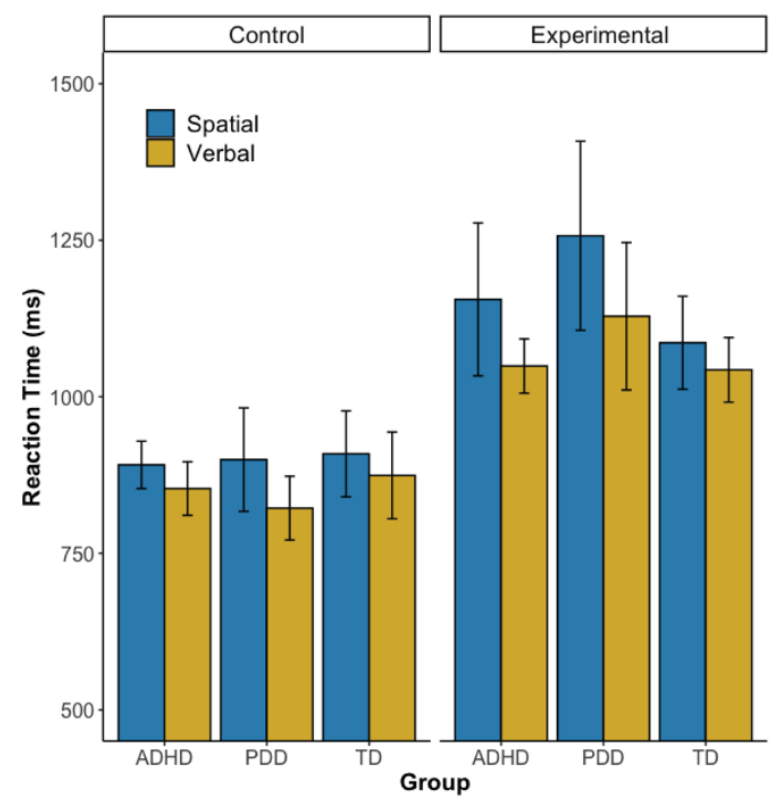

b

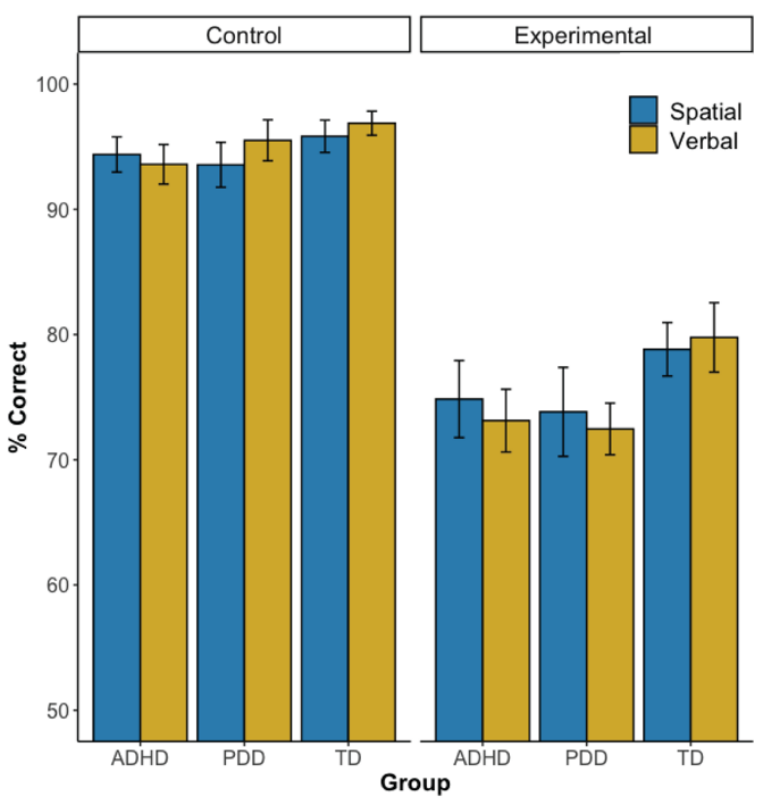

Figure 2: a) Reaction Time by Experimental and Control Condition. Participants were overall slower when performing the experimental conditions relative to the control conditions. Although RT performance was similar between verbal and spatial memory tasks, there was a slight trend towards faster RT in the verbal condition in the PDD group. For both plots, error bars indicate standard error. b) Accuracy by Experimental and Control Condition. Participants were overall less accurate when performing the experimental conditions relative to the control conditions. For each group, the accuracy did not differ between verbal and spatial memory task components. 


\section{Multivariate Decoding Results (MVPA)}

We applied a linear SVM to a priori brain networks and identified disorder-specific classification accuracies that indicate the distinctness of spatial vs. verbal working memory task representations within each network. These networks are shown in Figure 3a. Table 2 presents the cross-validated classification accuracy minus chance (chance $=50 \%$ ) from the decoding analyses for each ROI. Our primary focus was on the left and right FPN within each group. For both networks, we expected to observe significant classification accuracies in the TD group indicative of differential neural representations of verbal and spatial working memory. Indeed, the TD group showed significantly above chance classification accuracies within both the left $(p=.001)$ and right $(p<.001)$ FPN. For the ADHD group, significant classification accuracies were observed within the left FPN $(\mathrm{p}=.034)$ and right FPN $(p=.035)$, but both were lower than the TD group. For the PDD group, classification accuracy was not significant in the left FPN ( $p=.223)$, but was statistically significant within the right $\operatorname{FPN}(p=0.030)$.

Additionally, we included the SN and DMN as networks of interest due to their known interactions with the FPN and prior work indicating aberrant within and across network functions in both ADHD and PDD. For the TD group, both the SN $(p<.001)$ and DMN $(p=.004)$ exhibited significant classification accuracies. For the PDD group, only the $\mathrm{SN}(p<.001)$ but not the DMN $(p=.074)$ exhibited significant classification accuracy. Conversely, for the ADHD group, classification accuracy was significant in the DMN $(p=.003)$ but not in the $\mathrm{SN}(p=.309)$.

We also examined the classification accuracies of the spatial vs. verbal control conditions (trials that matched the experimental working memory trials in all aspects with the exception of the delay period, thus removing the memory component of the task). None of the classification accuracies for these control conditions were significant in the TD group, suggesting that spatial 
and verbal information does not per se elicit differential processing in the right and left FPN, DMN and SN. In the PDD and ADHD groups, we observed the same pattern as in the TD group in the left and right FPN and SN. However, the DMN showed significant differential processing of verbal and spatial material in the control condition for both the PDD group $(p=.021)$ and ADHD group $(\mathrm{p}=.003)$.

Lastly, we examined the SM as a control network, and predicted that classification accuracies would be similar in all three groups with little differentiation between verbal and spatial processes. Unexpectedly, in all three groups classification accuracy was significantly high for the working memory trials. For the control trials, we did not observe significant differentiation for TD and ADHD groups, but observed significant classification accuracy for the PDD group ( $p=0.004)$. Figure $3 \mathrm{~b}$ displays the classification accuracy minus chance across ROIs, delineated for each group.

Table 2: Within Groups Classification Accuracy Minus Chance for each group and region of interest separately for the experimental (working memory) and control condition.

\begin{tabular}{|c|c|c|c|c|c|c|}
\hline & \multicolumn{2}{|c|}{ Experimental Condition } & \multicolumn{4}{|c|}{ Control Condition } \\
\hline & TD & ADHD & PDD & TD & ADHD & PDD \\
\hline $\begin{array}{l}\text { Left } \\
\text { Frontoparietal }\end{array}$ & $\begin{array}{l}42.11 * * * \\
(p<0.001)\end{array}$ & $\begin{array}{c}17.50^{*} \\
(p=0.034)\end{array}$ & $\begin{array}{c}9.38 \\
(p=0.223)\end{array}$ & $\begin{array}{c}13.16 \\
(p=0.097)\end{array}$ & $\begin{array}{c}10.00 \\
(p=0.200)\end{array}$ & $\begin{array}{c}3.13 \\
(p=0.419)\end{array}$ \\
\hline $\begin{array}{l}\text { Right } \\
\text { Frontoparietal }\end{array}$ & $\begin{array}{l}34.21 * * * \\
(p<0.001)\end{array}$ & $\begin{array}{c}17.50^{*} \\
(p=0.035)\end{array}$ & $\begin{array}{c}18.75^{*} \\
(p=0.030)\end{array}$ & $\begin{array}{c}13.16 \\
(p=0.104)\end{array}$ & $\begin{array}{c}12.5 \\
(p=0.130)\end{array}$ & $\begin{array}{c}3.13 \\
(p=0.437)\end{array}$ \\
\hline Salience & $\begin{array}{l}23.68^{* * *} \\
(p<0.001)\end{array}$ & $\begin{array}{c}5.00 \\
(p=0.309)\end{array}$ & $\begin{array}{l}37.50 * * * \\
(p<0.001)\end{array}$ & $\begin{array}{c}-10.53 \\
(p=0.871)\end{array}$ & $\begin{array}{c}2.50 \\
(p=0.440)\end{array}$ & $\begin{array}{c}15.63 \\
(p=0.109)\end{array}$ \\
\hline Default Mode & $\begin{array}{c}28.94 * * \\
(p=0.004)\end{array}$ & $\begin{array}{c}27.50 * * \\
(p=0.003)\end{array}$ & $\begin{array}{c}15.63 \\
(p=0.074)\end{array}$ & $\begin{array}{c}0.00 \\
(p=0.526)\end{array}$ & $\begin{array}{c}25.00 * * \\
(p=0.003)\end{array}$ & $\begin{array}{c}21.88^{*} \\
(p=0.021)\end{array}$ \\
\hline Sensorimotor & $\begin{array}{c}23.32 * * \\
(p=0.002)\end{array}$ & $\begin{array}{c}17.50^{*} \\
(p=0.026)\end{array}$ & $\begin{array}{c}28.13 * * \\
(p=0.002)\end{array}$ & $\begin{array}{c}13.15 \\
(p=0.099)\end{array}$ & $\begin{array}{c}7.50 \\
(p=0.235)\end{array}$ & $\begin{array}{c}28.13 * * \\
(p=0.004)\end{array}$ \\
\hline
\end{tabular}


bioRxiv preprint doi: https://doi.org/10.1101/2021.03.09.434662; this version posted July 16, 2021. The copyright holder for this preprint (which was not certified by peer review) is the author/funder, who has granted bioRxiv a license to display the preprint in perpetuity. It is made available under aCC-BY-ND 4.0 International license.

a

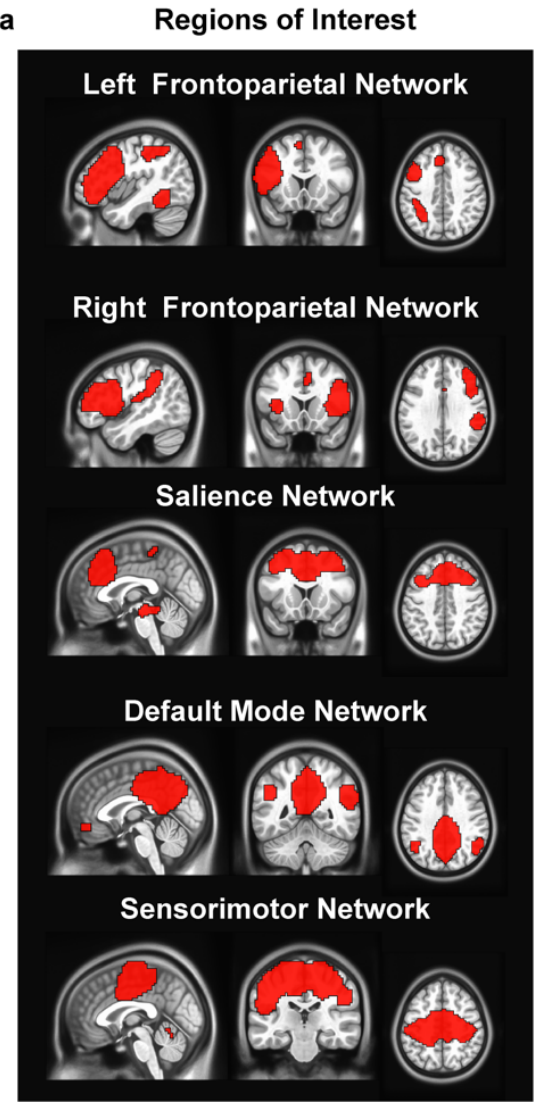

b Within-Groups Classification Accuracy of Verbal vs. Spatial Working Memory

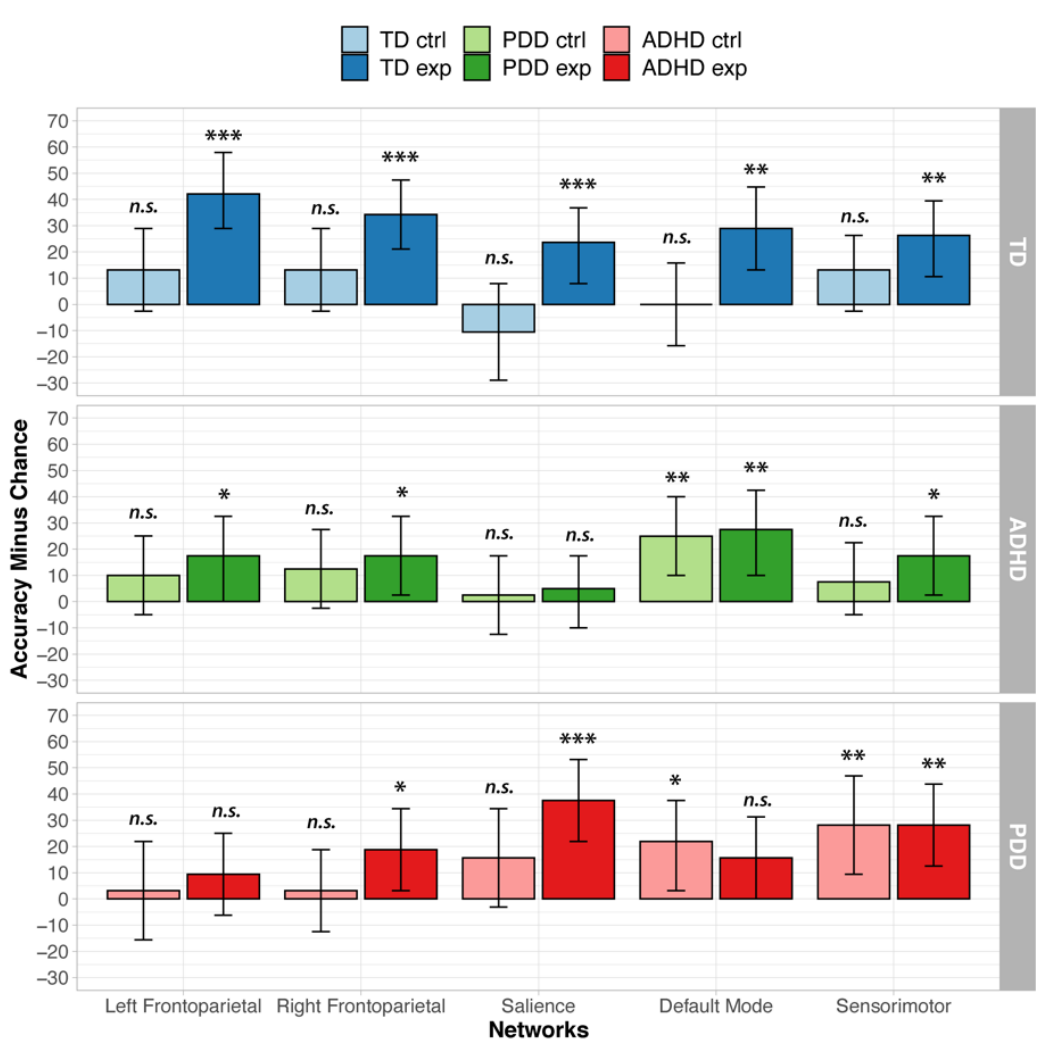

Figure 3 a) Regions of Interest. Left and Right Frontoparietal Network (LFPN and RFPN) forming as the primary ROIs for working memory function, followed by the Salience Network (SN) and Default Mode Network (DMN) known to interact with the FPN. The sensorimotor network (SM) served as control ROI. b) Within-Groups Classification Accuracy of Spatial vs. Verbal Working Memory for the five selected networks. Here, the classification accuracy indicates the distinctness of spatial vs. verbal working memory task representations within each ROI. Importantly, utilization of the same ROI for each decoding facilitates clear comparison of how neural representations of working memory tasks may differ across clinical groups. High classification accuracies are observed across all networks but with group specific patterns. The TD group shows distinguishable patterns of verbal and spatial working memory processes in all networks. Classification accuracies are significantly high for the right FPN, salience and sensorimotor networks but not the left FPN or DMN in the PDD group. For the ADHD group we observed significant classification accuracies only in the DMN with a trend for the left FPN. Error bars represent $90 \%$ confidence intervals, and statistical significance is listed for one-tailed permutation tests: ${ }^{*} \mathrm{p}<.05 ;{ }^{* *} \mathrm{p}<.01 ;{ }^{* * *} \mathrm{p}<.001$. Permutation distributions for each ROI, condition, and group are illustrated in Figure S2 in the Supplementary Material.

\section{ROC and AUC Metrics for Comparison Between Groups}

In order to facilitate quantitative comparison of the classification model performance between ROI networks and groups, we utilized signal detection metrics and estimated the receiver operator characteristic (ROC) curve and area under the ROC curve (AUC) metrics. The ROC curve reflects a combination of the model's sensitivity (i.e., proportion of true positive 
assessments) and specificity (i.e., proportion of true negative assessments), which can be used to compute an AUC measure of classifier performance for each network and each group. Critically, as the AUC measure considers the tradeoff between true positive rate and false positive rate, it provides a more comprehensive measure to compare classifier performance in each network between groups. Greater detail of how these signal detection metrics is derived and calculated are described in the Supplementary Material, and a table of all of the metrics is provided (Table S3).

In both left and right FPN, the AUC is higher in the TD group $\left(\mathrm{AUC}_{\mathrm{TD}}=97.5\right.$ (left) and 85.32 (right)) compared to the $\mathrm{ADHD}$ and $\mathrm{PDD}$ groups $\left(\mathrm{AUC}_{\mathrm{ADHD}}=73.5\right.$ (left) and 65.25 (right); $\mathrm{AUC}_{\mathrm{PDD}}=66.02$ (left) and 73.83 (right)), suggesting better classification performance of spatial vs. verbal working processes for the TD group compared to either clinical group in both FPN networks (e.g., lower false positive rates and higher true positive rates).

Interestingly, the pattern of ROC curves was different for both the SN and the DMN. Specifically, within the SN, the AUC was highest for the PDD group (AUC PDD $=97.5)$, followed by the $\mathrm{TD}$ group $\left(\mathrm{AUC}_{\mathrm{TD}}=77.84\right)$, and close to chance for the $\mathrm{ADHD}$ group $\left(\mathrm{AUC} \mathrm{ADHD}_{\mathrm{A}}=56.5\right)$. Within the DMN, the AUC was similar for both $\mathrm{TD}$ and $\mathrm{ADHD}$ groups $\left(\mathrm{AUC}_{\mathrm{TD}}=84.49\right.$, $\left.\mathrm{AUC}_{\mathrm{ADHD}}=84\right)$, and were both higher than the $\mathrm{AUC}$ for the PDD group $\left(\mathrm{AUC}_{\mathrm{PDD}}=74.22\right)$. Finally, within the SM network, the AUC is similar for both TD and PDD groups $\left(\mathrm{AUC}_{\mathrm{TD}}=80.61\right.$, $\left.\mathrm{AUC}_{\mathrm{PDD}}=83.59\right)$, which was higher than the $\mathrm{ADHD}$ group $\left(\mathrm{AUC}_{\mathrm{ADHD}}=68.25\right)$. Figure $4 \mathrm{a}$ plots each group's ROC curve by network and 4b provides corresponding group AUC metrics. 
a Receiver Operating Characteristic (ROC) Curves by Network

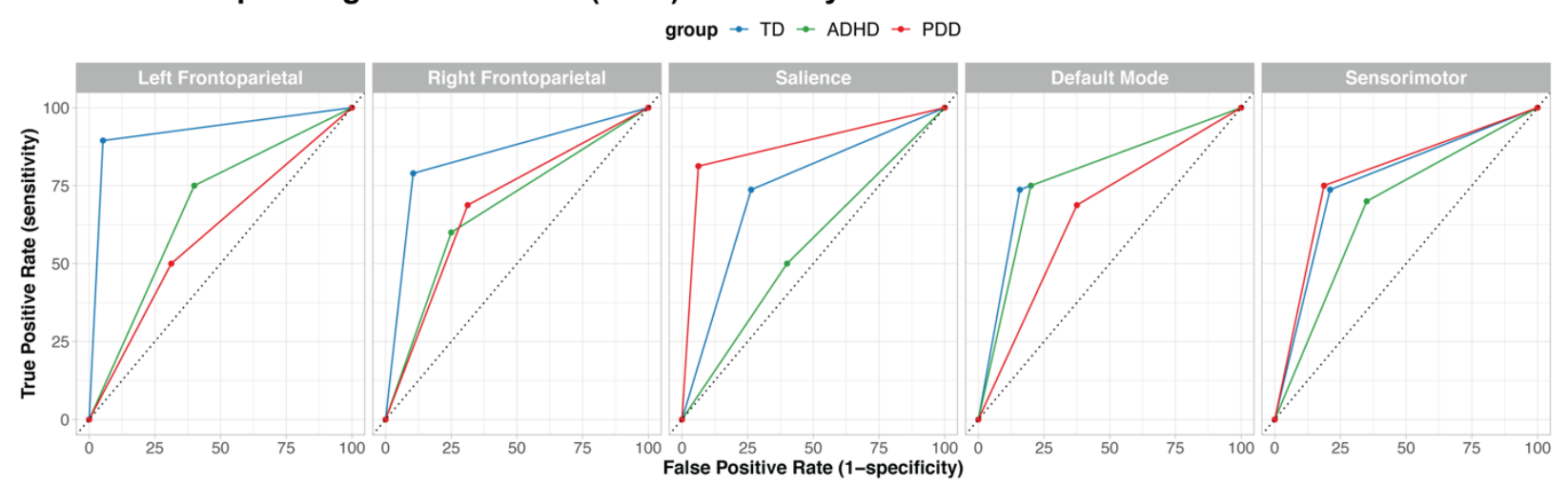

b Area Under the ROC Curve (AUC) Metrics by Network

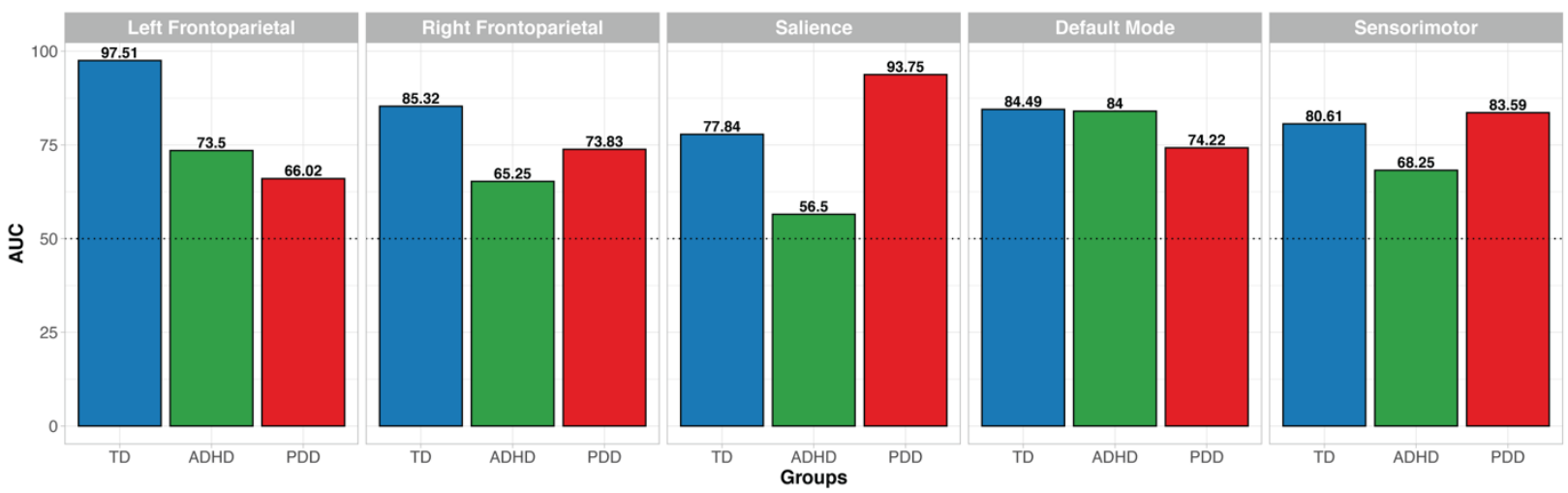

Figure 4 a) Receiver Operating Characteristic (ROC) Curves by ROI Network and Group. These empirical ROC curves reflect the combination of the linear SVM's sensitivity (true positive rate) and specificity (false positive rate), which we combine to compute an area under the ROC curve (AUC) measure of classifier performance for the control condition. The colored lines indicate the ROC curves for TD (blue), ADHD (green), and PDD (red) groups. The black diagonal dotted line indicates chance performance. b) Area Under the ROC Curve (AUC) By ROI Network and Group. Notably, the AUC measures are highest for the TD group in both left and right Frontoparietal Networks (FPN), whereas the AUC is highest for the PDD group in the Salience Network (SN). The highest AUC measures in the Default Mode Network (DMN) are similar for both TD and ADHD groups. The black dotted line indicates chance performance.

\section{Whole Brain Univariate Results for Spatial and Verbal Working Memory Tasks}

In order to verify that the fMRI task reliably activated key working memory related regions, we averaged whole-brain activations for spatial and verbal working memory experimental conditions for each group (TD, ADHD, PDD). Our results revealed that all groups show expected activation in left and right FPN and SN, as well as expected deactivation the DMN. Importantly, similar activation of these networks across all groups provide evidence that these key working 
bioRxiv preprint doi: https://doi.org/10.1101/2021.03.09.434662; this version posted July 16, 2021. The copyright holder for this preprint (which was not certified by peer review) is the author/funder, who has granted bioRxiv a license to display the preprint in perpetuity. It is made available under aCC-BY-ND 4.0 International license.

MVPA OF WORKING MEMORY IN ADHD AND DEPRESSION

memory networks are involved in both spatial and verbal tasks. Averaged beta estimations for each group are shown in Figure 5, and MNI coordinates of peak activations for all conditions are shown in Table S4 in the Supplemental Material.

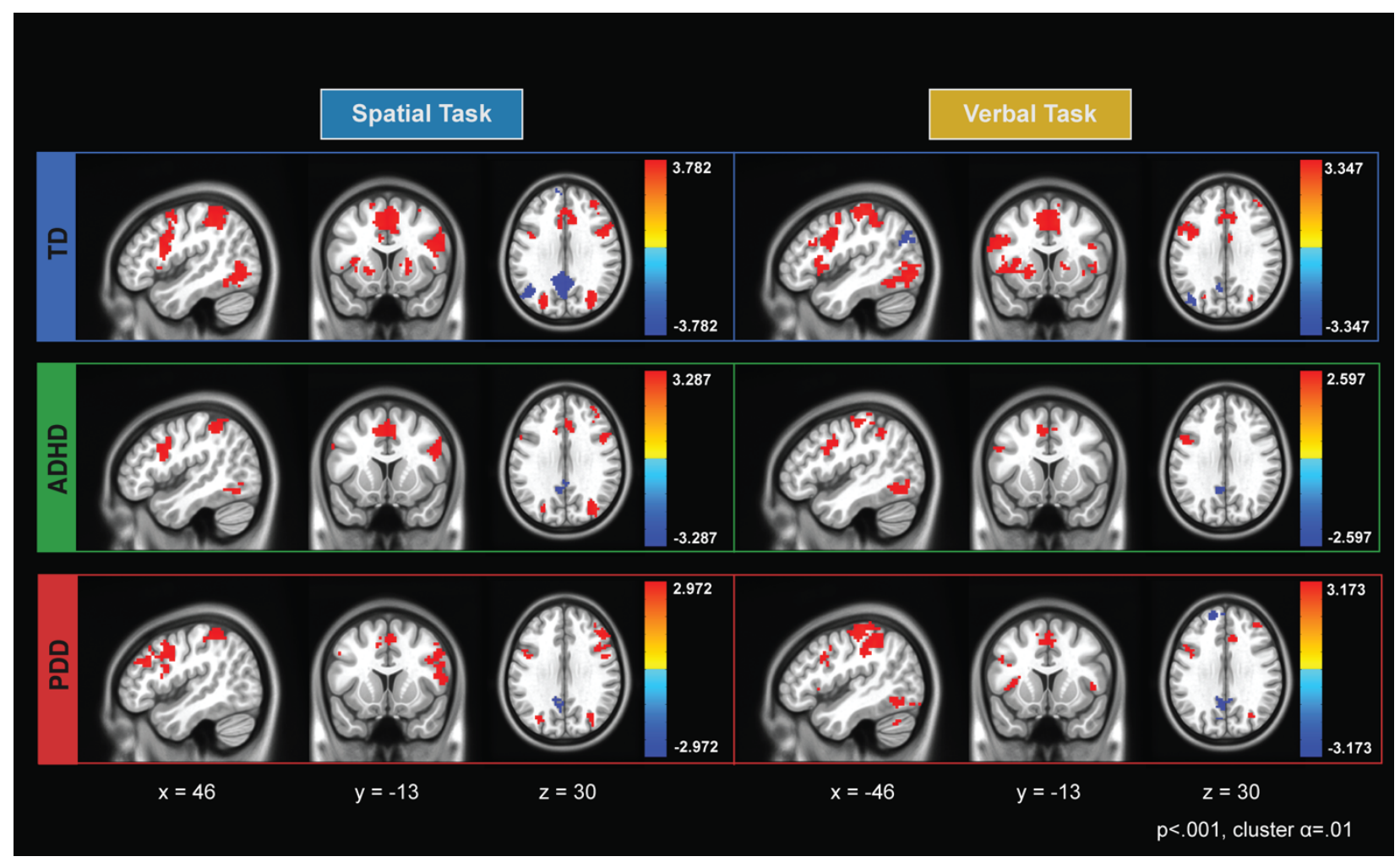

Figure 5: Whole-brain activations for the spatial and verbal working memory experimental condition in typical development, ADHD, and PDD groups. These results revealed all groups show expected activation in key working memory related regions (e.g., left and right frontoparietal networks, salience network) and expected deactivation in default mode network for both spatial and verbal tasks. Importantly, these data show consistent activation in these networks across all groups for both spatial and verbal tasks, which markedly deviate from the neural profiles of clinical groups that were established from the MVPA decoding analyses. Significant clusters were thresholded at $p<.001$ and cluster corrected with a threshold of $\alpha=.01$. The colors correspond to t-values, with yellow-red associated with positive values and blues associated with negative values.

\section{Discussion}

In this study, we identified distinct neural profiles for spatial versus verbal working memory processes in frontoparietal, salience, and default mode networks in boys with ADHD, 
boys with PDD, and typically developing male youth. We used a novel approach that combined MVPA and network-based analyses to compare multivariate neural representations of verbal and spatial working memory within each group. Our approach revealed clear distinguishable neural patterns in the TD group in a priori networks not observed in either clinical group. The PDD group differentially processed verbal and spatial material in right but not left FPN while classification accuracies in the ADHD group showed significant differential processing in both networks. Comparing across groups and in line with our predictions, we observe a higher AUC value in the left FPN and a lower value for the right FPN in the ADHD compared to the PDD group. Classifier performance in these networks was lower in both clinical groups characterized by both, lower sensitivity and specificity than in the TD group. The neural profiles of the clinical groups also suggest differential contributions of the $\mathrm{SN}$ and $\mathrm{DMN}$ in the processing of spatial vs. verbal working memory with a clear demarcation in the SN (but not DMN) in PDD, and the DMN (but not $\mathrm{SN}$ ) in ADHD.

The TD group's neural profile shows clear distinctions between verbal and spatial working memory processes across all networks. In contrast, no differential processing of verbal and spatial material was observed in control conditions. The highest classification accuracies were observed in the left and right FPN, demonstrating known lateralized processes such as verbal rehearsal (left $>$ right) (Nagel et al., 2013) or spatial information processing (right $>$ left) (Ray et al., 2008). The significant classification accuracies in the DMN may be attributed to greater involvement of posterior DMN regions in mental imagery (i.e., precuneus), supporting retention of non-verbal material (Cavanna \& Trimble, 2006). Lastly, the significant distinctiveness found in the SN likely suggests that one type of information, verbal or spatial, may be more or less salient in the context of working memory. 
The PDD group revealed a neural profile of significant differentiation between verbal and spatial working memory in the right FPN and SN, and non-significant differentiation in the left FPN and DMN. Interestingly, both left and right FPN show no differential processing of verbal and spatial material in the control condition, whereas only the right FPN revealed differential processing during the working memory condition. This pattern suggests that pediatric PDD may be associated with a failure to trigger specialized processing patterns in the left FPN during working memory, consistent with prior work implicating aberrant functioning of left FPN during working memory tasks in adults with depression (Vasic et al., 2007; Walter et al., 2007). Differentiation between verbal and spatial processes in the DMN was detected during the control condition and not during the experimental condition, a pattern opposite to the one observed in the TD group. Studies showing opposing activation and functional connectivity patterns of the FPN, DMN and SN between adult patients with depression and non-depressed individuals have reported compensatory mechanism in these networks which support successful working memory performance in patients but not in controls and vice versa (Albert et al., 2019; Harvey et al., 2005). The unique neural profile seen in the PDD group therefore likely reflects both pathophysiological mechanisms in some networks such as the left FPN as well as compensatory mechanisms in DMN or SN.

With the exception of the SN, the ADHD group's neural profile indicates differentiation of verbal and spatial working memory processes in all networks. Both left and right FPN show differential processing, although AUC values are lower than in the TD group and marginally better for the left than for the right FPN. The results for the SN suggest saliency detection and dynamic switching between networks are not sufficiently different between the verbal and spatial tasks. In contrast, significant classification in the DMN in both the experimental and the control condition 
suggests processing differences between the two tasks that are not specific to working memory. DMN altered within and between network connectivity as well as increased activity in this network during cognitive tasks is a common finding in patients with ADHD, and has been associated with excessive mind-wandering, attentional lapses and impaired intertemporal decision making (Bozhilova et al., 2018; Castellanos et al., 2009; Sonuga-Barke et al., 2016; Sonuga-Barke \& Castellanos, 2007). Our results suggest that the neural response patterns in the DMN are sensitive to the task context and behave differently whether verbal or spatial stimuli are presented. As the FPN, SN and DMN are tightly connected and work together for optimal cognitive performance (Menon, 2011), suboptimal function in just one network likely has effects on the functioning of the other. Future studies may therefore want to examine more closely the between network dynamics that result in deviant neural processing in the SN and DMN observed here to inform neurobiological mechanisms underpinning working memory deficits in pediatric ADHD.

Additionally, we included the sensorimotor network as a control analysis and expected comparable classification accuracies across groups. For the working memory conditions, all three groups show significant differential processing of verbal and spatial tasks, with similar AUCs for the TD and PDD group and with a lower AUC for the ADHD group. Unexpectedly, for the control condition the PDD group also showed high classification accuracy which was not observed in the two other groups. Although the tasks were closely matched, and we did not observe significant behavioral differences in RT and accuracy, we cannot exclude the possibility that other systematic differences may have contributed to the distinct neural patterns observed in the SM and other networks. 
Lastly, in addition to our within-group classification analyses, we also examined signal detection metrics from the linear SVM to compare classifier performance across groups. In particular, our ROC/AUC results revealed that for all networks the classifier performed better in the TD group than in the clinical groups during the working memory condition. The exception here is the $\mathrm{SN}$, for which the classifier performed better in the PDD group compared to the other two groups, and this increased AUC measure appears to be driven by both higher specificity and sensitivity. Overall, our results confirm our hypotheses and are consistent with the large body of research that has shown differences in the neural underpinnings between patient groups diagnosed with ADHD or clinical depression and non-clinical groups during working memory tasks (e.g., Burgess et al., 2010; Matsuo et al., 2007; Mills et al., 2012; Vance et al., 2007; Vilgis et al., 2014; Walter et al., 2007; Wolf et al., 2009). Group differences in classifier performance during the control condition most notable in the DMN and $\mathrm{SN}$ are particularly intriguing, as resting-state investigations have previously shown atypical functional connectivity of these networks at rest in patients with ADHD and patients with clinical depression (e.g., Cortese et al., 2021; Mulders et al., 2015; Sundermann et al., 2014; Sutcubasi et al., 2020). Broadly, these results provide novel information regarding disorder-specific neural profiles during working memory, which have important implications given the high comorbidity of the two disorders. Although both disorders have repeatedly been associated with abnormal function and connectivity in the core networks investigated in the current study, we demonstrate not only differences between the clinical groups and typically developing youth but also between the clinical samples. Future studies should aim to delineate how divergent network function during working memory contributes to different disorders or even distinct psychiatric symptom dimensions, which may be informative for 
elucidating the potential behavioral or cognitive factors that drive unique or divergent neural profiles of youth with ADHD and youth with depressive disorders.

We acknowledge important limitations, including the lack of spatial specificity (i.e., which voxels within each network are most distinct) or whether deviant responses to either the verbal or spatial task (or both) contributed to significant differentiation of neural patterns. Additionally, although we opted to collapse across the load-component of the two tasks to increase the reliability of the beta-estimates for the classification analysis, more systematic evaluation of working memory load in subsequent studies may help identify additional clinically relevant neural processing patterns in typical and atypical development. Nevertheless, by separately examining the working memory and control conditions we were able to show clear distinctions between more cognitively demanding and simple perceptual processes, respectively. Another technical consideration relates the limited temporal resolution of our beta estimates, due to the relatively slow TR $(2.7 \mathrm{~s})$ and blocked design of the working memory paradigm. Future studies may opt to capitalize upon recent advances in multiband acquisition sequences (Bhandari et al., 2020; Risk et al., 2021) that will allow for shorter TR measurements and improve temporal specificity of beta estimates used for MVPA or other types of multivariate analyses. Notably, although our sample well-matched across groups (thus making it well-suited for multivariate pattern classification), it was relatively small and focused on only male participants within a limited age range, which may restrict the generalizability of the results. It is also not clear to what extent out results may apply to adults with ADHD or PDD. However, up to 94\% of individuals with early onset PDD (i.e., before the age of 21) report a subsequent a major depressive episode at some point in their life (Klein et al., 2000) suggesting neural alterations early on may constitute a vulnerability for later depression and likely stay constant or worsen with age. For those with ADHD, between $50 \%$ to 
$60 \%$ show persistence of symptoms into adulthood (Roy et al., 2016), particularly symptoms of inattention that are more closely linked to executive function deficits such as working memory. As such, while studies in adults are necessary to confirm the transferability of our findings, we believe the findings and methodology equally applies to adults with the disorder. Finally, although our small sample is well characterized clinically, it is not well-suited for diagnostic (i.e., betweensubjects) classification. Future studies could use classification approaches to predict whether dissociable network patterns predict clinical diagnoses (Nielsen et al., 2020; Saeed, 2018; Sundermann et al., 2014) or subtypes within diagnosis (Fair et al., 2013). Such investigations could focus on transdiagnostic measures, which entails predicting symptom dimensions rather than categorical diagnoses, as proposed by the Research Domain Criteria Framework (Buckholtz \& Meyer-Lindenberg, 2012; Cuthbert \& Insel, 2013; Parkes et al., 2020).

\section{Conclusion}

In conclusion, we highlight within-group classification as an innovative approach to identify the distinctness of neural response patterns in a priori brain networks across two neurodevelopmental disorders. We found group-specific neural profiles comprising networkspecific spatial vs. verbal working memory processes. The neural profile of the TD group is characterized by distinct neural response patterns when retaining spatial vs. verbal information in working memory, suggesting greater specialization for and sensitivity to task demands in several key networks supporting essential cognitive, emotional and social functions. The neural profiles of both clinical groups markedly deviate from the control group, hinting at neural representations putatively less responsive to varying task demands. Identifying group-specific neural profiles of essential cognitive processes in health and disease is a much-needed intermediary step to advance 
bioRxiv preprint doi: https://doi.org/10.1101/2021.03.09.434662; this version posted July 16, 2021. The copyright holder for this preprint (which

was not certified by peer review) is the author/funder, who has granted bioRxiv a license to display the preprint in perpetuity. It is made available under aCC-BY-ND 4.0 International license.

translational psychiatry and to help inform dysregulated brain mechanisms (Huys et al., 2016; Woo et al., 2017). Critically, we demonstrate that data-driven multivariate approaches can advance further investigation into how brain networks underpinning cognitive processes may differ between clinical disorders (Yoon et al., 2008), ultimately improving the translation of research to inform clinical diagnosis and treatment. 


\section{Acknowledgments}

This research was conducted within the Developmental Imaging research group, Murdoch Children's Research Institute and the Academic Child Psychiatry Unit, Department of Paediatrics, The University of Melbourne. Royal Children's Hospital, Melbourne, Victoria. It was supported by the Murdoch Children's Research Institute, the Royal Children's Hospital, The Royal Children's Hospital Foundation, Department of Paediatrics, The University of Melbourne, and the

Victorian Government's Operational Infrastructure Support Program. TS was supported by a NHMRC Career Development Award. DY was supported by the National Institutes of Health NRSA Fellowship F31-DA042574. We would like to thank all children and families who participated in this research. We would also like to thank Dr. Lauren Richmond for helpful comments on the manuscript. DY and VV would also like to thank the Kavli Foundation for enabling participation in their Summer School in Cognitive Neuroscience (2016, Santa Barbara, USA), where this collaboration originated.

\section{Disclosures}

Dr. Yee, Dr. Vilgis, Dr. Silk and Dr. Vance all report no biomedical financial interests or potential conflicts of interest.

\section{Open Practices Statement}

The data and materials for all experiments are available on our OSF repository: https://osf.io/a5349/. The experiment was not preregistered. 


\section{References}

Achenbach, T. (1991). Manual for the Child Behavior Checklist/4-18 and 1991 profile. University of Vermont, Department of Psychiatry.

Albert, K. M., Potter, G. G., Boyd, B. D., Kang, H., \& Taylor, W. D. (2019). Brain network functional connectivity and cognitive performance in major depressive disorder. Journal of Psychiatric Research, 110, 51-56. https://doi.org/10.1016/j.jpsychires.2018.11.020

Allefeld, C., \& Haynes, J.-D. (2014). Searchlight-based multi-voxel pattern analysis of fMRI by cross-validated MANOVA. NeuroImage, 89, 345-357. https://doi.org/10.1016/j.neuroimage.2013.11.043

American Psychiatric Association (Ed.). (2000). Diagnostic and statistical manual of mental disorders: DSM-IV-TR (4th ed., text revision). American Psychiatric Association.

Arnsten, A. F. T., \& Rubia, K. (2012). Neurobiological Circuits Regulating Attention, Cognitive Control, Motivation, and Emotion: Disruptions in Neurodevelopmental Psychiatric Disorders. Journal of the American Academy of Child \& Adolescent Psychiatry, 51(4), 356-367. https://doi.org/10.1016/j.jaac.2012.01.008

Barch, D. M., Sheline, Y. I., Csernansky, J. G., \& Snyder, A. Z. (2003). Working memory and prefrontal cortex dysfunction: Specificity to schizophrenia compared with major depression. Biological Psychiatry, 53(5), 376-384. https://doi.org/10.1016/S00063223(02)01674-8

Beauregard, M., Paquette, V., \& Le'vesque, J. (2006). Dysfunction in the neural circuitry of emotional self-regulation in major depressive disorder. NeuroReport, 17(8), 843-846. https://doi.org/10.1097/01.wnr.0000220132.32091.9f 
Bhandari, R., Kirilina, E., Caan, M., Suttrup, J., De Sanctis, T., De Angelis, L., Keysers, C., \& Gazzola, V. (2020). Does higher sampling rate (multiband + SENSE) improve group statistics-An example from social neuroscience block design at 3T. NeuroImage, 213, 116731. https://doi.org/10.1016/j.neuroimage.2020.116731

Bozhilova, N. S., Michelini, G., Kuntsi, J., \& Asherson, P. (2018). Mind wandering perspective on attention-deficit/hyperactivity disorder. Neuroscience \& Biobehavioral Reviews, 92, 464-476. https://doi.org/10.1016/j.neubiorev.2018.07.010

Buckholtz, J. W., \& Meyer-Lindenberg, A. (2012). Psychopathology and the Human Connectome: Toward a Transdiagnostic Model of Risk For Mental Illness. Neuron, 74(6), 990-1004. https://doi.org/10.1016/j.neuron.2012.06.002

Burgess, G. C., Depue, B. E., Ruzic, L., Willcutt, E. G., Du, Y. P., \& Banich, M. T. (2010). Attentional Control Activation Relates to Working Memory in AttentionDeficit/Hyperactivity Disorder. Biological Psychiatry, 67(7), 632-640. https://doi.org/10.1016/j.biopsych.2009.10.036

Cai, W., Griffiths, K., Korgaonkar, M. S., Williams, L. M., \& Menon, V. (2019). Inhibitionrelated modulation of salience and frontoparietal networks predicts cognitive control ability and inattention symptoms in children with ADHD. Molecular Psychiatry. https://doi.org/10.1038/s41380-019-0564-4

Castellanos, F. X., Kelly, C., \& Milham, M. P. (2009). The Restless Brain: Attention-Deficit Hyperactivity Disorder, Resting-State Functional Connectivity, and Intrasubject Variability. The Canadian Journal of Psychiatry, 54(10), 665-672. https://doi.org/10.1177/070674370905401003 
Cavanna, A. E., \& Trimble, M. R. (2006). The precuneus: A review of its functional anatomy and behavioural correlates. Brain, 129(3), 564-583. https://doi.org/10.1093/brain/awl004

Chow, T. E., Westphal, A. J., \& Rissman, J. (2018). Multi-voxel pattern classification differentiates personally experienced event memories from secondhand event knowledge. NeuroImage, 176, 110-123. https://doi.org/10.1016/j.neuroimage.2018.04.024

Cole, M. W., Bassett, D. S., Power, J. D., Braver, T. S., \& Petersen, S. E. (2014). Intrinsic and Task-Evoked Network Architectures of the Human Brain. Neuron, 83(1), 238-251. https://doi.org/10.1016/j.neuron.2014.05.014

Conners, C. K., Sitarenios, G., Parker, J. D. A., \& Epstein, J. N. (1998). The revised Conners' Parent Rating Scale (CPRS-R): Factor structure, reliability, and criterion validity. Journal of Abnormal Child Psychology, 26(4), 257-268.

https://doi.org/10.1023/A:1022602400621

Cortese, S., Aoki, Y. Y., Itahashi, T., Castellanos, F. X., \& Eickhoff, S. B. (2021). Systematic Review and Meta-analysis: Resting-State Functional Magnetic Resonance Imaging Studies of Attention-Deficit/Hyperactivity Disorder. Journal of the American Academy of Child \& Adolescent Psychiatry, 60(1), 61-75. https://doi.org/10.1016/j.jaac.2020.08.014

Cortese, S., Kelly, C., Chabernaud, C., Proal, E., Di Martino, A., Milham, M. P., \& Castellanos, F. X. (2012). Toward Systems Neuroscience of ADHD: A Meta-Analysis of $55 \mathrm{fMRI}$ Studies. American Journal of Psychiatry, 169(10), 1038-1055. https://doi.org/10.1176/appi.ajp.2012.11101521

Cox, R. W. (1996). AFNI: Software for Analysis and Visualization of Functional Magnetic Resonance Neuroimages. Computers and Biomedical Research, 29(3), 162-173. https://doi.org/10.1006/cbmr.1996.0014 
Crawford, J. R., Anderson, V., Rankin, P. M., \& MacDonald, J. (2010). An index-based shortform of the WISC-IV with accompanying analysis of the reliability and abnormality of differences. British Journal of Clinical Psychology, 49(2), 235-258. https://doi.org/10.1348/014466509X455470

Cuthbert, B. N., \& Insel, T. R. (2013). Toward the future of psychiatric diagnosis: The seven pillars of RDoC. BMC Medicine, 11(1), 126. https://doi.org/10.1186/1741-7015-11-126

Daniel, T. A., Katz, J. S., \& Robinson, J. L. (2016). Delayed match-to-sample in working memory: A BrainMap meta-analysis. Biological Psychology, 120, 10-20. https://doi.org/10.1016/j.biopsycho.2016.07.015

Dwyer, D. B., Falkai, P., \& Koutsouleris, N. (2018). Machine Learning Approaches for Clinical Psychology and Psychiatry. Annual Review of Clinical Psychology, 14(1), 91-118. https://doi.org/10.1146/annurev-clinpsy-032816-045037

Etzel, J. A., \& Braver, T. S. (2013). MVPA Permutation Schemes: Permutation Testing in the Land of Cross-Validation. 2013 International Workshop on Pattern Recognition in Neuroimaging, 140-143. https://doi.org/10.1109/PRNI.2013.44

Etzel, J. A., Cole, M. W., Zacks, J. M., Kay, K. N., \& Braver, T. S. (2016). Reward Motivation Enhances Task Coding in Frontoparietal Cortex. Cerebral Cortex, 26(4), 1647-1659. https://doi.org/10.1093/cercor/bhu327

Fair, D. A., Nigg, J. T., Iyer, S., Bathula, D., Mills, K. L., Dosenbach, N. U. F., Schlaggar, B. L., Mennes, M., Gutman, D., Bangaru, S., Buitelaar, J. K., Dickstein, D. P., Di Martino, A., Kennedy, D. N., Kelly, C., Luna, B., Schweitzer, J. B., Velanova, K., Wang, Y.-F., ... Milham, M. P. (2013). Distinct neural signatures detected for ADHD subtypes after 
controlling for micro-movements in resting state functional connectivity MRI data.

Frontiers in Systems Neuroscience, 6. https://doi.org/10.3389/fnsys.2012.00080

Franklin, T., Lee, A., Hall, N., Hetrick, S., Ong, J., Haslam, N., Karsz, F., \& Vance, A. (2010).

The association of visuospatial working memory with dysthymic disorder in pre-pubertal children. Psychological Medicine, 40(2), 253-261.

https://doi.org/10.1017/S0033291709990365

Gardumi, A., Ivanov, D., Hausfeld, L., Valente, G., Formisano, E., \& Uludağ, K. (2016). The effect of spatial resolution on decoding accuracy in fMRI multivariate pattern analysis. NeuroImage, 132, 32-42. https://doi.org/10.1016/j.neuroimage.2016.02.033

Gohier, B., Ferracci, L., Surguladze, S. A., Lawrence, E., El Hage, W., Kefi, M. Z., Allain, P., Garre, J.-B., \& Le Gall, D. (2009). Cognitive inhibition and working memory in unipolar depression. Journal of Affective Disorders, 116(1-2), 100-105.

https://doi.org/10.1016/j.jad.2008.10.028

Gruber, O., Zilles, D., Kennel, J., Gruber, E., \& Falkai, P. (2011). A systematic experimental neuropsychological investigation of the functional integrity of working memory circuits in major depression. European Archives of Psychiatry and Clinical Neuroscience, 261(3), 179-184. https://doi.org/10.1007/s00406-010-0165-3

Günther, T., Holtkamp, K., Jolles, J., Herpertz-Dahlmann, B., \& Konrad, K. (2004). Verbal memory and aspects of attentional control in children and adolescents with anxiety disorders or depressive disorders. Journal of Affective Disorders, 82(2), 265-269. https://doi.org/10.1016/j.jad.2003.11.004

Hamilton, J. L., Stange, J. P., Shapero, B. G., Connolly, S. L., Abramson, L. Y., \& Alloy, L. B. (2013). Cognitive Vulnerabilities as Predictors of Stress Generation in Early 
Adolescence: Pathway to Depressive Symptoms. Journal of Abnormal Child Psychology, 41(7), 1027-1039. https://doi.org/10.1007/s10802-013-9742-z

Harvey, P.-O., Fossati, P., Pochon, J.-B., Levy, R., LeBastard, G., Lehéricy, S., Allilaire, J.-F., \& Dubois, B. (2005). Cognitive control and brain resources in major depression: An fMRI study using the n-back task. NeuroImage, 26(3), 860-869.

https://doi.org/10.1016/j.neuroimage.2005.02.048

Haxby, J. V., Connolly, A. C., \& Guntupalli, J. S. (2014). Decoding Neural Representational Spaces Using Multivariate Pattern Analysis. Annual Review of Neuroscience, 37(1), 435456. https://doi.org/10.1146/annurev-neuro-062012-170325

Haynes, J.-D. (2015). A Primer on Pattern-Based Approaches to fMRI: Principles, Pitfalls, and Perspectives. Neuron, 87(2), 257-270. https://doi.org/10.1016/j.neuron.2015.05.025

Hebart, M. N., \& Baker, C. I. (2018). Deconstructing multivariate decoding for the study of brain function. NeuroImage, 180, 4-18. https://doi.org/10.1016/j.neuroimage.2017.08.005

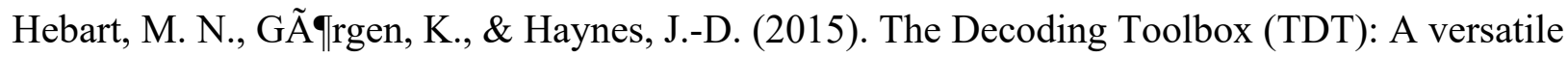
software package for multivariate analyses of functional imaging data. Frontiers in Neuroinformatics, 8. https://doi.org/10.3389/fninf.2014.00088

Huys, Q. J. M., Maia, T. V., \& Frank, M. J. (2016). Computational psychiatry as a bridge from neuroscience to clinical applications. Nature Neuroscience, 19(3), 404-413. https://doi.org/10.1038/nn.4238

Kessler, R. C., Angermeyer, M., Anthony, J. C., DE Graaf, R., Demyttenaere, K., Gasquet, I., DE Girolamo, G., Gluzman, S., Gureje, O., Haro, J. M., Kawakami, N., Karam, A., Levinson, D., Medina Mora, M. E., Oakley Browne, M. A., Posada-Villa, J., Stein, D. J., Adley Tsang, C. H., Aguilar-Gaxiola, S., ... Ustün, T. B. (2007). Lifetime prevalence and 
age-of-onset distributions of mental disorders in the World Health Organization's World Mental Health Survey Initiative. World Psychiatry: Official Journal of the World Psychiatric Association (WPA), 6(3), 168-176.

Klein, D. N., Schwartz, J. E., Rose, E., \& Leader, J. B. (2000). Five-Year Course and Outcome of Dysthymic Disorder: A Prospective, Naturalistic Follow-Up Study. American Journal of Psychiatry, 157(6), 931-939. https://doi.org/10.1176/appi.ajp.157.6.931

Klimkeit, E. I., Mattingley, J. B., Sheppard, D. M., Lee, P., \& Bradshaw, J. L. (2005). MOTOR PREPARATION, MOTOR EXECUTION, ATTENTION, AND EXECUTIVE FUNCTIONS IN ATTENTION DEFICIT/HYPERACTIVITY DISORDER (ADHD). Child Neuropsychology, 11(2), 153-173. https://doi.org/10.1080/092970490911298

Korhonen, V., Laukkanen, E., Antikainen, R., Peiponen, S., Lehtonen, J., \& Viinamäki, H. (2002). Effect of major depression on cognitive performance among treatment-seeking adolescents. Nordic Journal of Psychiatry, 56(3), 187-193. https://doi.org/10.1080/080394802317607165

Kovacs, M. (2003). The Children's Depression Inventory (CDI). Multi-Health System.

Kovacs, M., Joormann, J., \& Gotlib, I. H. (2008). Emotion (Dys)regulation and Links to Depressive Disorders. Child Development Perspectives, 2(3), 149-155. https://doi.org/10.1111/j.1750-8606.2008.00057.x

Ku, S., Gretton, A., Macke, J., \& Logothetis, N. K. (2008). Comparison of pattern recognition methods in classifying high-resolution BOLD signals obtained at high magnetic field in monkeys. Magnetic Resonance Imaging, 26(7), 1007-1014.

https://doi.org/10.1016/j.mri.2008.02.016 
Liang, X., Zou, Q., He, Y., \& Yang, Y. (2016). Topologically Reorganized Connectivity Architecture of Default-Mode, Executive-Control, and Salience Networks across Working Memory Task Loads. Cerebral Cortex, 26(4), 1501-1511. https://doi.org/10.1093/cercor/bhu316

Maalouf, F. T., Brent, D., Clark, L., Tavitian, L., McHugh, R. M., Sahakian, B. J., \& Phillips, M. L. (2011). Neurocognitive impairment in adolescent major depressive disorder: State vs. trait illness markers. Journal of Affective Disorders, 133(3), 625-632. https://doi.org/10.1016/j.jad.2011.04.041

Manoliu, A., Meng, C., Brandl, F., Doll, A., Tahmasian, M., Scherr, M., Schwerthöffer, D., Zimmer, C., Förstl, H., Bäuml, J., Riedl, V., Wohlschläger, A. M., \& Sorg, C. (2014). Insular dysfunction within the salience network is associated with severity of symptoms and aberrant inter-network connectivity in major depressive disorder. Frontiers in Human Neuroscience, 7. https://doi.org/10.3389/fnhum.2013.00930

Martel, M. (2007). Executive Function in Adolescents With ADHD. J. AM. ACAD. CHILD ADOLESC. PSYCHIATRY, 8.

Martinussen, R., Ed, M., Hayden, J., \& Tannock, R. (2005). A Meta-Analysis of Working Memory Impairments in Children With Attention-Deficit/Hyperactivity Disorder. J. AM. ACAD. CHILD ADOLESC. PSYCHIATRY, 8.

Matsuo, K., Glahn, D. C., Peluso, M. A. M., Hatch, J. P., Monkul, E. S., Najt, P., Sanches, M., Zamarripa, F., Li, J., Lancaster, J. L., Fox, P. T., Gao, J.-H., \& Soares, J. C. (2007). Prefrontal hyperactivation during working memory task in untreated individuals with major depressive disorder. Molecular Psychiatry, 12(2), 158-166. https://doi.org/10.1038/sj.mp.4001894 
Matthews, K., Coghill, D., \& Rhodes, S. (2008). Neuropsychological functioning in depressed adolescent girls. Journal of Affective Disorders, 111(1), 113-118.

https://doi.org/10.1016/j.jad.2008.02.003

Menon, V. (2011). Large-scale brain networks and psychopathology: A unifying triple network model. Trends in Cognitive Sciences, 15(10), 483-506.

https://doi.org/10.1016/j.tics.2011.08.003

Menon, V., \& Uddin, L. Q. (2010). Saliency, switching, attention and control: A network model of insula function. Brain Structure and Function, 214(5-6), 655-667.

https://doi.org/10.1007/s00429-010-0262-0

Miller, C. H., Hamilton, J. P., Sacchet, M. D., \& Gotlib, I. H. (2015). Meta-analysis of Functional Neuroimaging of Major Depressive Disorder in Youth. JAMA Psychiatry, 72(10), 1045. https://doi.org/10.1001/jamapsychiatry.2015.1376

Mills, K. L., Bathula, D., Dias, T. G. C., Iyer, S. P., Fenesy, M. C., Musser, E. D., Stevens, C. A., Thurlow, B. L., Carpenter, S. D., Nagel, B. J., Nigg, J. T., \& Fair, D. A. (2012). Altered Cortico-Striatal-Thalamic Connectivity in Relation to Spatial Working Memory Capacity in Children with ADHD. Frontiers in Psychiatry, 3. https://doi.org/10.3389/fpsyt.2012.00002

Mulders, P. C., van Eijndhoven, P. F., Schene, A. H., Beckmann, C. F., \& Tendolkar, I. (2015). Resting-state functional connectivity in major depressive disorder: A review. Neuroscience \& Biobehavioral Reviews, 56, 330-344. https://doi.org/10.1016/j.neubiorev.2015.07.014 
Mumford, J. A., Turner, B. O., Ashby, F. G., \& Poldrack, R. A. (2012). Deconvolving BOLD activation in event-related designs for multivoxel pattern classification analyses. NeuroImage, 59(3), 2636-2643. https://doi.org/10.1016/j.neuroimage.2011.08.076

Nagel, B. J., Herting, M. M., Maxwell, E. C., Bruno, R., \& Fair, D. (2013). Hemispheric lateralization of verbal and spatial working memory during adolescence. Brain and Cognition, 82(1), 58-68. https://doi.org/10.1016/j.bandc.2013.02.007

Nielsen, A. N., Barch, D. M., Petersen, S. E., Schlaggar, B. L., \& Greene, D. J. (2020). Machine Learning With Neuroimaging: Evaluating Its Applications in Psychiatry. Biological Psychiatry: Cognitive Neuroscience and Neuroimaging, 5(8), 791-798. https://doi.org/10.1016/j.bpsc.2019.11.007

Parkes, L., Satterthwaite, T. D., \& Bassett, D. S. (2020). Towards precise resting-state fMRI biomarkers in psychiatry: Synthesizing developments in transdiagnostic research, dimensional models of psychopathology, and normative neurodevelopment. Current Opinion in Neurobiology, 65, 120-128. https://doi.org/10.1016/j.conb.2020.10.016

Pereira, F., Mitchell, T., \& Botvinick, M. (2009). Machine learning classifiers and fMRI: A tutorial overview. NeuroImage, 45(1), S199-S209. https://doi.org/10.1016/j.neuroimage.2008.11.007

Ray, M. K., Mackay, C. E., Harmer, C. J., \& Crow, T. J. (2008). Bilateral Generic Working Memory Circuit Requires Left-Lateralized Addition for Verbal Processing. Cerebral Cortex, 18(6), 1421-1428. https://doi.org/10.1093/cercor/bhm175

Risk, B. B., Murden, R. J., Wu, J., Nebel, M. B., Venkataraman, A., Zhang, Z., \& Qiu, D. (2021). Which multiband factor should you choose for your resting-state fMRI study? NeuroImage, 234, 117965. https://doi.org/10.1016/j.neuroimage.2021.117965 
Rose, E. J., Simonotto, E., \& Ebmeier, K. P. (2006). Limbic over-activity in depression during preserved performance on the n-back task. NeuroImage, 29(1), 203-215. https://doi.org/10.1016/j.neuroimage.2005.07.002

Rottschy, C., Langner, R., Dogan, I., Reetz, K., Laird, A. R., Schulz, J. B., Fox, P. T., \& Eickhoff, S. B. (2012). Modelling neural correlates of working memory: A coordinatebased meta-analysis. NeuroImage, 60(1), 830-846. https://doi.org/10.1016/j.neuroimage.2011.11.050

Roy, A., Hechtman, L., Arnold, L. E., Sibley, M. H., Molina, B. S. G., Swanson, J. M., Howard, A. L., Vitiello, B., Severe, J. B., Jensen, P. S., Arnold, L. E., Hoagwood, K., Richters, J., Vereen, D., Hinshaw, S. P., Elliott, G. R., Wells, K. C., Epstein, J. N., Murray, D. W., ... Stern, K. (2016). Childhood Factors Affecting Persistence and Desistence of AttentionDeficit/Hyperactivity Disorder Symptoms in Adulthood: Results From the MTA. Journal of the American Academy of Child \& Adolescent Psychiatry, 55(11), 937-944.e4. https://doi.org/10.1016/j.jaac.2016.05.027

Saeed, F. (2018). Towards quantifying psychiatric diagnosis using machine learning algorithms and big fMRI data. Big Data Analytics, 3(1), 7. https://doi.org/10.1186/s41044-018-00330

Seeley, W. W. (2019). The Salience Network: A Neural System for Perceiving and Responding to Homeostatic Demands. The Journal of Neuroscience, 39(50), 9878-9882. https://doi.org/10.1523/JNEUROSCI.1138-17.2019

Shaw, P., Ch, M. B. B., Stringaris, A., Nigg, J., \& Leibenluft, E. (2014). Emotion Dysregulation in Attention Deficit Hyperactivity Disorder. Am J Psychiatry, 18. 
Shilyansky, C., Williams, L. M., Gyurak, A., Harris, A., Usherwood, T., \& Etkin, A. (2016).

Effect of antidepressant treatment on cognitive impairments associated with depression:

A randomised longitudinal study. The Lancet Psychiatry, 3(5), 425-435.

https://doi.org/10.1016/S2215-0366(16)00012-2

Silk, T., Vance, A., Rinehart, N., Egan, G., O’Boyle, M., Bradshaw, J. L., \& Cunnington, R. (2005). Fronto-parietal activation in attention-deficit hyperactivity disorder, combined type: Functional magnetic resonance imaging study. British Journal of Psychiatry, 187(3), 282-283. https://doi.org/10.1192/bjp.187.3.282

Silverman, W. K., Saavedra, L. M., \& Pina, A. A. (2001). Test-Retest Reliability of Anxiety Symptoms and Diagnoses With the Anxiety Disorders Interview Schedule for DSM-IV: Child and Parent Versions. Journal of the American Academy of Child \& Adolescent Psychiatry, 40(8), 937-944. https://doi.org/10.1097/00004583-200108000-00016

Smith, S. M., Fox, P. T., Miller, K. L., Glahn, D. C., Fox, P. M., Mackay, C. E., Filippini, N., Watkins, K. E., Toro, R., Laird, A. R., \& Beckmann, C. F. (2009). Correspondence of the brain's functional architecture during activation and rest. Proceedings of the National Academy of Sciences, 106(31), 13040-13045. https://doi.org/10.1073/pnas.0905267106

Sonuga-Barke, E. J. S., \& Castellanos, F. X. (2007). Spontaneous attentional fluctuations in impaired states and pathological conditions: A neurobiological hypothesis. Neuroscience \& Biobehavioral Reviews, 31(7), 977-986.

https://doi.org/10.1016/j.neubiorev.2007.02.005

Sonuga-Barke, E. J. S., Cortese, S., Fairchild, G., \& Stringaris, A. (2016). Annual Research Review: Transdiagnostic neuroscience of child and adolescent mental disorders differentiating decision making in attention-deficit/hyperactivity disorder, conduct 
disorder, depression, and anxiety. Journal of Child Psychology and Psychiatry, 57(3), 321-349. https://doi.org/10.1111/jcpp.12496

Sowerby, P., Seal, S., \& Tripp, G. (2011). Working Memory Deficits in ADHD: The Contribution of Age, Learning/Language Difficulties, and Task Parameters. Journal of Attention Disorders, 15(6), 461-472. https://doi.org/10.1177/1087054710370674

Sundermann, B., Herr, D., Schwindt, W., \& Pfleiderer, B. (2014). Multivariate Classification of Blood Oxygen Level-Dependent fMRI Data with Diagnostic Intention: A Clinical Perspective. American Journal of Neuroradiology, 35(5), 848-855. https://doi.org/10.3174/ajnr.A3713

Sutcubasi, B., Metin, B., Kurban, M. K., Metin, Z. E., Beser, B., \& Sonuga-Barke, E. (2020). Resting-state network dysconnectivity in ADHD: A system-neuroscience-based metaanalysis. The World Journal of Biological Psychiatry, 21(9), 662-672.

https://doi.org/10.1080/15622975.2020.1775889

Thomason, M. E., Race, E., Burrows, B., Whitfield-Gabrieli, S., Glover, G. H., \& Gabrieli, J. D. E. (2009). Development of Spatial and Verbal Working Memory Capacity in the Human Brain. Journal of Cognitive Neuroscience, 21(2), 316-332.

https://doi.org/10.1162/jocn.2008.21028

Vance, A., Silk, T. J., Casey, M., Rinehart, N. E., Bradshaw, J. L., Bellgrove, M. A., \& Cunnington, R. (2007). Right parietal dysfunction in children with attention deficit hyperactivity disorder, combined type: A functional MRI study. Molecular Psychiatry, 12(9), 826-832. https://doi.org/10.1038/sj.mp.4001999

Vance, A., \& Winther, J. (2020). Irritability, Depressed Mood, Inattention and Spatial Working Memory in Children and Adolescents with Major Depressive Disorder With/Without 
Persistent Depressive Disorder. Child Psychiatry \& Human Development.

https://doi.org/10.1007/s10578-020-01061-x

Vasic, N., Wolf, R. C., \& Walter, H. (2007). Exekutive Funktionen bei depressiven Patienten:

Zur Rolle der präfrontalen Aktivierung. Der Nervenarzt, 78(6), 628-640.

https://doi.org/10.1007/s00115-006-2240-6

Vilgis, V., Chen, J., Silk, T. J., Cunnington, R., \& Vance, A. (2014). Frontoparietal function in young people with dysthymic disorder (DSM-5: Persistent depressive disorder) during spatial working memory. Journal of Affective Disorders, 160, 34-42.

https://doi.org/10.1016/j.jad.2014.01.024

Vilgis, V., Silk, T. J., \& Vance, A. (2015). Executive function and attention in children and adolescents with depressive disorders: A systematic review. European Child \& Adolescent Psychiatry, 24(4), 365-384. https://doi.org/10.1007/s00787-015-0675-7

Walter, H., Wolf, R. C., Spitzer, M., \& Vasic, N. (2007). Increased left prefrontal activation in patients with unipolar depression: An event-related, parametric, performance-controlled fMRI study. Journal of Affective Disorders, 101(1-3), 175-185. https://doi.org/10.1016/j.jad.2006.11.017

Wechsler, D. (2003). Wechsler intelligence scale for children - Fourth edition (WISC-IV). The Psychological Corporation.

Wiecki, T. V., Poland, J., \& Frank, M. J. (2015). Model-Based Cognitive Neuroscience Approaches to Computational Psychiatry: Clustering and Classification. Clinical Psychological Science, 3(3), 378-399. https://doi.org/10.1177/2167702614565359

Willcutt, E. G., Doyle, A. E., Nigg, J. T., Faraone, S. V., \& Pennington, B. F. (2005). Validity of the Executive Function Theory of Attention-Deficit/Hyperactivity Disorder: A Meta- 
Analytic Review. Biological Psychiatry, 57(11), 1336-1346.

https://doi.org/10.1016/j.biopsych.2005.02.006

Wisniewski, D., Reverberi, C., Momennejad, I., Kahnt, T., \& Haynes, J.-D. (2015). The Role of the Parietal Cortex in the Representation of Task-Reward Associations. Journal of Neuroscience, 35(36), 12355-12365. https://doi.org/10.1523/JNEUROSCI.4882-14.2015

Wolf, R. C., Plichta, M. M., Sambataro, F., Fallgatter, A. J., Jacob, C., Lesch, K.-P., Herrmann, M. J., Schönfeldt-Lecuona, C., Connemann, B. J., Grön, G., \& Vasic, N. (2009). Regional brain activation changes and abnormal functional connectivity of the ventrolateral prefrontal cortex during working memory processing in adults with attention-deficit/hyperactivity disorder. Human Brain Mapping, 30(7), 2252-2266. https://doi.org/10.1002/hbm.20665

Woo, C.-W., Chang, L. J., Lindquist, M. A., \& Wager, T. D. (2017). Building better biomarkers: Brain models in translational neuroimaging. Nature Neuroscience, 20(3), 365-377. https://doi.org/10.1038/nn.4478

Woolgar, A., Afshar, S., Williams, M. A., \& Rich, A. N. (2015). Flexible Coding of Task Rules in Frontoparietal Cortex: An Adaptive System for Flexible Cognitive Control. Journal of Cognitive Neuroscience, 27(10), 1895-1911.https://doi.org/10.1162/jocn_a_00827

Yang, Z., Fang, F., \& Weng, X. (2012). Recent developments in multivariate pattern analysis for functional MRI. Neuroscience Bulletin, 28(4), 399-408. https://doi.org/10.1007/s12264$012-1253-3$

Yoon, J. H., Tamir, D., Minzenberg, M. J., Ragland, J. D., Ursu, S., \& Carter, C. S. (2008). Multivariate Pattern Analysis of Functional Magnetic Resonance Imaging Data Reveals 
bioRxiv preprint doi: https://doi.org/10.1101/2021.03.09.434662; this version posted July 16, 2021. The copyright holder for this preprint (which

was not certified by peer review) is the author/funder, who has granted bioRxiv a license to display the preprint in perpetuity. It is made available under aCC-BY-ND 4.0 International license.

MVPA OF WORKING MEMORY IN ADHD AND DEPRESSION

Deficits in Distributed Representations in Schizophrenia. Biological Psychiatry, 64(12),

1035-1041. https://doi.org/10.1016/j.biopsych.2008.07.025

Zhu, W., Zeng, N. F., \& Wang, N. (2010). Sensitivity, Specificity, Accuracy, Associated

Confidence Interval and ROC Analysis with Practical SAS. 